\title{
Synthetic Cell Surface Receptors for Delivery of Therapeutics and Probes
}

\author{
David Hymel and Blake R. Peterson* \\ Department of Medicinal Chemistry, The University of Kansas, Lawrence, KS 66045, United \\ States
}

\begin{abstract}
Receptor-mediated endocytosis is a highly efficient mechanism for cellular uptake of membraneimpermeant ligands. Cells use this process to acquire nutrients, initiate signal transduction, promote development, regulate neurotransmission, and maintain homeostasis. Natural receptors that participate in receptor-mediated endocytosis are structurally diverse, ranging from large transmembrane proteins to small glycolipids embedded in the outer leaflet of cellular plasma membranes. Despite their vast structural differences, these receptors share common features of binding to extracellular ligands, clustering in dynamic membrane regions that pinch off to yield intracellular vesicles, and accumulation of receptor-ligand complexes in membrane-sealed endosomes. Receptors typically dissociate from ligands in endosomes and cycle back to the cell surface, whereas internalized ligands are usually delivered into lysosomes, where they are degraded, but some can escape and penetrate into the cytosol. Here, we review efforts to develop synthetic cell surface receptors, defined as nonnatural compounds, exemplified by mimics of cholesterol, that insert into plasma membranes, bind extracellular ligands including therapeutics, probes, and endogenous proteins, and engage endocytic membrane trafficking pathways. By mimicking natural mechanisms of receptor-mediated endocytosis, synthetic cell surface receptors have the potential to function as prosthetic molecules capable of seamlessly augmenting the endocytic uptake machinery of living mammalian cells.
\end{abstract}

\section{Keywords}

Receptors; ligands; cholesterol; lipids; endocytosis; trafficking; recycling; delivery; endosomes; membranes; fluorescence; vancomycin

\section{Receptor-mediated endocytosis}

The plasma membrane of eukaryotic cells represents a universal barrier that protects fragile intracellular structures from toxic or detrimental extracellular materials. Whereas small hydrophobic molecules can often penetrate this lipid bilayer through passive diffusion, polar amino acids, sugars and ions must interact with specific membrane-bound protein pumps or channels to access the cell interior. Other cell-impermeable small molecules, macromolecules, and particles, must be actively taken up by cells, with regions of the plasma membrane functioning to capture solutes by invaginating and pinching off to form

(C) 2012 Elsevier B.V. All rights reserved.

*brpeters@ku.edu, Fax: (785) 864-8141.

Publisher's Disclaimer: This is a PDF file of an unedited manuscript that has been accepted for publication. As a service to our customers we are providing this early version of the manuscript. The manuscript will undergo copyediting, typesetting, and review of the resulting proof before it is published in its final citable form. Please note that during the production process errors may be discovered which could affect the content, and all legal disclaimers that apply to the journal pertain. 
intracellular vesicles. This process, termed endocytosis, represents multiple related mechanisms for the internalization of extracellular molecules.[1-3] These mechanisms include phagocytosis, where specific cell types engulf large particles, pinocytosis, where small regions of cellular plasma membranes are actively invaginated to capture solutes, and receptor-mediated endocytosis (RME). In RME, internalizing receptors on the cell surface bind cell-impermeable ligands to concentrate these ligands in the cell, providing a mechanism of cellular uptake that is thousands of times more efficient than non-specific pinocytosis.

Receptors involved in RME comprise a structurally diverse group of biomolecules. These receptors range from macromolecular proteins that span the plasma membrane to small glycolipids, anchored only to the plasma membrane outer leaflet. Cell-impermeable small molecules, lipids, peptides, proteins, nucleic acids, and carbohydrates can be internalized by RME, enabling the consumption of nutrients, elimination of pathogens, and termination of signals initiated by extracellular stimuli. By exploiting RME, certain viruses, protein toxins, and other pathogens invade cells and cause disease.[4] These pathogens include simian virus-40 (SV40), which enters cells through RME upon binding to the small glycolipid ganglioside GM1 (M.W. $1603 \mathrm{~g} / \mathrm{mol}$ ). Figure 1 shows structures of the protein capsid of this virus[5] and a side view of the VP1 pentamer subunit[6] that binds the pentasaccharide head group of ganglioside GM1. This figure also shows structures of extracellular regions and representations of other receptors involved in RME such as the membrane-spanning lowdensity lipoprotein (LDL) receptor,[7] the transferrin receptor (TFR), [8] and the lipidanchored receptor Fc $\gamma$ RIIIB (CD16)[9] bound to or below the cognate ligands LDL,[10] transferrin, and the Fc fragment of human IgG.

RME of cholesterol-laden LDL particles by the LDL receptor (LDLR) has been extensively characterized,[7, 11-14] and key features of this process are illustrated in Figure 2. The LDLR binds LDL particles defined by a core of $\sim 1500$ molecules of fatty acid-esterified cholesterol that is encapsulated by a monolayer of free cholesterol, phospholipids, triglycerides, and a single protein termed apolipoprotein B-100. By recognizing the protein component of LDL, the LDLR provides a major mechanism by which vertebrate animals internalize exogenous cholesterol, a key building block required for the biosynthesis of steroid hormones and bile acids, and the assembly of cellular membranes. By binding the cytosolic protein clathrin, the LDLR clusters in clathrin-coated pits on the cellular plasma membrane. Association of the LDLR with clathrin requires interactions between cytosolic residues of this receptor with adapter proteins such as ARH, $[15,16]$ which associates with phosphatidylinositol-4,5-bisphosphate at the cytofacial leaflet of the plasma membrane. These interactions allow the LDLR to constitutively deliver LDL into membrane-sealed vesicles that fuse to form endosomes (Figure 2). In this process, clathrin polymerizes to form a lattice of clathrin hexagons and pentagons that surround vesicles as they bud from the plasma membrane. Changes in membrane curvature required for vesicle budding are stabilized both by clathrin and a number of clathrin-binding proteins including FCHO proteins that drive flat plasma membrane segments into highly curved endocytic vesicles loaded with cargo.[1] The $\mathrm{pH}$ of these internalized vesicles drops as a consequence of activation of proton pumps and opening of chloride channels, and these vesicles fuse with relatively short-lived acidic $(\mathrm{pH} \sim 6)$ sorting endosomes that accept receptor ligand complexes. $[17,18]$ This decrease in $\mathrm{pH}$, and the intrinsic tubular-vesicular geometry of sorting endosomes, facilitates the dissociation of receptors from ligands.[19] Many free receptors subsequently traffic to the endocytic-recycling compartment (ERC), a long-lived organelle, before cycling back to the cell surface. In this way, the LDLR can be reused up to several hundred times during its $\sim 20$-hour lifespan. Sorting endosomes containing free LDL mature to form more acidic late endosomes $(\mathrm{pH} \sim 5.5)$, and these compartments subsequently fuse with lysosomes, more acidic organelles $(\mathrm{pH} \sim 5)$ containing highly 
hydrolytic enzymes. Hydrolysis in lysosomes of cholesteryl esters, protein, and other components of LDL, liberates these nutrients for utilization by the cell.[11, 12] Because LDL is efficiently delivered to late endosomes and lysosomes (within $30 \mathrm{~min}$ ), fluorescent complexes of LDL[20] are often used as markers for these compartments at the terminal end of the endosomal pathway.

Clathrin-dependent endocytosis is thought to be responsible for the uptake of about half of all ligands of cell surface receptors. These ligands include LDL, epidermal growth factor (EGF), and transferrin (TF), a carrier of the essential nutrient iron in serum of vertebrate animals.[1] The TF protein binds the transferrin receptor (TFR), [8] and internalization of TF by RME results in release of iron in acidic endosomal compartments for utilization by the cell. However, unlike LDL, the apo-TF remains bound to its receptor, the receptor-ligand complex cycles back to the plasma membrane, and apo-TF is released from the TFR at the neutral $\mathrm{pH}$ of the extracellular environment. For this reason, fluorescent transferrin conjugates are often used to label early endosomes in studies of endocytic processes. Some receptors including LDLR and TFR are internalized via a constitutive clathrin-dependent pathway that does require ligand binding. In contrast, binding of EGF to the epidermal growth factor receptor (EGFR) and subsequent receptor dimerization is required to trigger clathrin-mediated endocytosis of this receptor.[21]

Some cell surface receptors are attached to the plasma membrane by lipids inserted into the exofacial leaflet of the bilayer. Posttranslational modification of proteins with glycosylphosphatidylinositol (GPI)-lipids is used to anchor receptors such as folate receptor-2 and Fc $\gamma$ RIIIB (CD16) on the cell surface. These receptors bind 5methyltetrahydrofolate $[22,23]$ and the invariant $F c$ region of immunoglobulin-G $[9,24]$ to promote RME of these ligands.[25] Similarly, small glycolipids function as receptors involved in RME. Ganglioside GM1 enables the protein cholera toxin[26] and the nonenveloped virus SV40 to enter cells upon binding to its pentasaccharide head group.[27, 28] Because of the lack of a direct connection to the highly efficient clathrin machinery via a cytoplasmic region, the endocytosis of GPI-linked proteins and other lipid-linked receptors is slower than the uptake of most transmembrane proteins, and is thought to involve multiple, possibly simultaneous, endocytic uptake mechanisms.[28] Uptake of lipid-bound ligands has been reported to involve lipid rafts, membrane domains enriched in cholesterol and sphingolipids, and in some cell types include flask shaped invaginations termed caveolae.[29] Many proteins covalently or noncovalently associated with cholesterol, sphingolipids, or saturated lipids associate with lipid rafts that segregate and concentrate membrane proteins, regulate signal transduction pathways, and can affect the endocytosis of specific receptors. Many lipid-linked proteins undergo endocytosis through clathrinindependent carriers (CLIC) and traffic through GPI-anchored protein-enriched early endosomal compartments (GEEC).[30] Other mechanisms of clathrin-independent endocytosis have also been reported, and this field was recently reviewed.[3, 31]

Protein toxins and viruses commonly exploit receptor-mediated endocytosis to penetrate into the cell interior.[4] In some cases, multiple distinct endocytic mechanisms of cellular uptake have been simultaneously observed.[32] In contrast to most protein ligands, viruses and other pathogens internalized by RME typically avoid degradation in lysosomes, either by engaging trafficking itineraries that bypass these organelles, by fusion of viral envelopes with endosomal membranes to escape from endosomes, or by production of proteins or peptides that disrupt endosomal or phagosomal membranes at low pH.[33] Here, we review recent efforts to develop synthetic molecules with trafficking properties similar to natural surface receptors. By inserting into cellular plasma membranes, these synthetic cell surface receptors are designed to promote the endocytosis of endogenous ligands, therapeutics, and 
molecular probes, and in some cases have been shown to enable escape of internalized cargo from endosomal compartments into the cytoplasm and nucleus of living cells.

\section{Cellular uptake and trafficking of cholesterol-mimetic membrane anchors}

Natural receptors are typically anchored to cell surfaces through either transmembrane protein segments or attached lipids such as GPI anchors and glycosphingolipids that insert into the exofacial leaflet of the plasma membrane. In contrast, cytoplasmic proteins are commonly anchored to intracellular membranes via other lipids such as palmitoyl thioesters, myristoyl amides, farnesyl and related thioethers, and cholesterol esters.[34, 35] Because of its high abundance in cellular plasma membranes, and its role in cycling between the cell surface and early/recycling endosomes,[36] we have focused on using analogues of cholesterol, particularly derivatives of cholesterylamine (Figure 3), to construct synthetic compounds that mimic cellular uptake and trafficking properties of natural cell surface receptors. A wide variety of synthetic mimics of other natural lipids[37-41] and peptides [42] capable of insertion into membranes of living cells have also been reported.

Cholesterol has been termed the central lipid of mammalian cells.[43] Among its many biological roles, this sterol is critically important for stabilization of animal cell membranes. To estimate the number of cholesterol molecules in cellular membranes, the plasma membrane of a typical mammalian cell was modeled by Maxfield[44] as a sphere of $10 \mu \mathrm{m}^{3}$ with a surface area of $3 \times 10^{8} \mathrm{~nm}^{2}$. This membrane is composed of approximately $2 / 3$ lipid and $1 / 3$ protein, and based on the average surface area of a lipid of $0.6 \mathrm{~nm}^{2}$, [45] contains about $10^{9}$ lipid molecules in both leaflets.[44] Because cholesterol represents about $30 \%$ of the lipids in the plasma membrane, the plasma membrane contains roughly $3 \times 10^{8}$ cholesterol molecules, corresponding to about half of the total abundance of cholesterol (about $6 \times 10^{8}$ molecules) in all membranes of mammalian cells. This sterol rapidly flips between the two leaflets of this membrane with a half-time of approximately 1 second,[46] but the distribution of cholesterol between leaflets of the plasma membrane is asymmetric, with a smaller fraction residing in the exofacial leaflet $\left(\sim 0.75 \times 10^{8}\right.$ molecules $)$, compared to the cytofacial leaflet $\left(\sim 2.25 \times 10^{8}\right.$ molecules).[36] Within cells, the ERC represents the second largest reservoir of cholesterol, containing about $2 \times 10^{8}$ molecules of this sterol. Photobleaching studies of the fluorescent natural product dehydroergosterol (Figure 3), a close structural and functional mimic of cholesterol, indicate that cholesterol dynamically cycles between the plasma membrane and ERC. In this rapid process, it has been estimated that $1 \times 10^{6}$ molecules of cholesterol enter and leave the ERC per second.[47] The cholesterol content of other mammalian organelles such as the endoplasmic reticulum (containing $\sim 5 \%$ of cellular cholesterol), the Golgi apparatus, lysosomes, and mitochondria is much lower than the plasma membrane and ERC. This heterogeneous distribution of cholesterol among biological membranes is thought to relate to the affinity of this sterol for saturated and monounsaturated lipids that are highly enriched in the plasma membrane and ERC compared to other organelles.[36]

The trafficking of cholesterol between the plasma membrane and the ERC has been proposed to occur through both vesicular (via endocytosis) and non-vesicular mechanisms. [44] However, a recent comparison of dehydroergosterol and fluorescent BODIPY cholesterol (Figure 3), in BHK cells engineered to express antisense mRNA against the heavy chain of clathrin, suggests that sterol internalization from the cell surface to the ERC occurs predominantly through vesicular uptake dependent on clathrin-mediated endocytosis. [48] Subsequent cycling of cholesterol from the ERC back to the plasma membrane is thought to involve vesicular transport similar to plasma membrane recycling of natural cell surface receptors.[44] Despite bearing a fluorophore in the tail of the sterol, BODIPY cholesterol appears to closely mimic the membrane trafficking and cellular efflux properties 
of natural cholesterol.[48-50] In contrast, other fluorescent sterols with modified tails such as 22-NBD cholesterol[51] and 25-NBD cholesterol[52] do not exhibit cellular trafficking properties similar to cholesterol. The use of fluorescent sterols to study cholesterol trafficking in living cells was recently reviewed.[53]

A wide variety of mimics and derivatives of cholesterol have been synthesized and investigated.[54] A comparison of the biophysical properties of the nonnatural compounds $3 \beta$-amino-5-cholestene (also known as cholesterylamine or aminocholesterol, Figure 3 ) and 3a-amino-5-cholestene was reported by Bittman in 1992.[55] These studies revealed that the $3 \beta$-isomer exhibits much slower biphasic vesicle exchange kinetics $\left(\mathrm{t}_{1 / 2}=118.9 \mathrm{~h}\right.$ and 9.3 h) compared with the $3 a$-isomer $\left(\mathrm{t}_{1 / 2}=393.1 \mathrm{~min}\right.$ and $\left.16.1 \mathrm{~min}\right)$ and free cholesterol (monophasic $t_{1 / 2}=256 \mathrm{~min}$ ). These results suggest the possibility of unique interactions between the $3 \beta$-isomer of cholesterylamine and phospholipids. Intrigued by these observations, we developed a practical method to synthesize multigram quantities of $3 \beta-$ cholesterylamine,[56] and we have investigated the biological properties of a variety of its derivatives. Some of our early work in this area[57-62] has been reviewed.[63]

Recent biophysical studies have investigated cholesterylamine in model bilayer membranes. [64] This synthetic steroid was found to form a liquid ordered phase very similar to cholesterol with saturated lipids, suggesting that cholesterylamine could be a good substitute for cholesterol. Consistent with this interpretation, fluorescent $N$-alkyl-cholesterylamines bearing neutral or negatively charged head groups such as Pennsylvania Green (PG)-Glu- $\beta$ Ala-cholesterylamine (1, Figure 3 ) are avidly taken up by living mammalian cells, associate with the cellular plasma membrane, and accumulate in transferrin-positive early/recycling endosomes (Figure 4, panels A-D). Although partitioning between the plasma membrane and early/recycling endosomes can differ depending on the structure of the head group and linker attached to cholesterylamine,[61] many of these compounds rapidly cycle between the plasma membrane and early/recycling endosomes. Some fluorescent cholesterylamine derivatives exhibit plasma membrane recycling kinetics similar to cycling of the LDL receptor, making a round trip between these two compartments in less than 10 minutes.[61] Structurally optimized fluorescent cholesterylamines such as $\mathbf{1}$ associate avidly with the exofacial leaflet of cellular plasma membranes and become localized in the ERC (see Figure 4, panels A-B), showing a overall distribution similar to the fluorescent cholesterol-binding macrolide filipin.[52] Many other fluorescent analogues of cholesterol are not stably incorporated in cellular plasma membranes. For example, confocal microscopy of Jurkat lymphocytes treated with 22-NBD cholesterol reveals rapid trafficking of this compound to the Golgi apparatus and nuclear membrane (see Figure 4, panels E-F).

By cycling between the plasma membrane and ERC of mammalian cells, cholesterylamines mimic some of the major membrane trafficking properties of natural cholesterol. However, the charged amino group of cholesterylamine also confers some significant biological differences compared with the alcohol of cholesterol in living cells. Whereas cholesterol can be esterified by fatty acids derived from phosphatidylcholine mediated by lecithin cholesterol acyltransferase (LCAT) for storage in lipoproteins and lipid droplets, [65] the predominantly protonated amino group of cholesterylamine and $\mathrm{N}$-alkyl-cholesterylamine derivatives is highly unlikely to be a substrate of this enzyme. Cholesterol also rapidly flips between leaflets of cellular membranes, [46] whereas desolvation of the protonated amino group of cholesterylamine engenders a substantial energetic penalty against equilibration across the leaflet of vesicles.[55] Consistent with this observation, studies of living Jurkat lymphocyte cells treated with $\mathrm{N}$-alkyl-cholesterylamines linked the $\mathrm{pH}$-sensitive hydrophobic Tokyo Green fluorophore[66] indicate that cholesterylamines do not flip between membrane leaflets. In these experiments, cellular fluorescence imaged by confocal microscopy was compared in the presence and absence of Bafilomycin A1,[67] a natural 
product inhibitor of vacuolar ATPases that raises endosomal $\mathrm{pH}$ and allows assessment of the abundance of the acid-sensitive Tokyo Green fluorophore in endosomes of treated cells. If this cholesterylamine had flipped to the cytofacial leaflet of endosomes, the linked Tokyo Green fluorophore would be exposed to the neutral $\mathrm{pH}$ of the cytoplasm, resulting in strong endosomal fluorescence. These experiments indicated that despite achieving a high relative abundance in the ERC, fluorescent cholesterylamines do not flip from the exofacial leaflet to the cytofacial leaflet of endosomal membranes of living cells.[66] As a consequence, cholesterylamines show dynamic membrane trafficking properties that are similar to many cell surface receptors, projecting $N$-linked groups either from the cell surface into the extracellular environment or from the exofacial leaflet of early/recycling endosomes into the lumen of these intracellular compartments during plasma membrane recycling.[61] This property allows the use of $\mathrm{N}$-alkyl-cholesterylamines and related compounds as a platform for the construction of mimics of cell surface receptors.

\section{Synthetic cell surface receptors comprising binding motifs linked to cholesterylamine}

\subsection{Fluorophores and other small protein-binding motifs}

Natural receptors involved in RME share a unifying structural architecture of projection of ligand-binding motifs from lipids or proteins embedded in the cellular plasma membrane. The smallest of these receptors associate with the exofacial leaflet of cellular plasma membranes through linked GPI-anchors and sphingolipids. Structures of the GPI anchor of human erythrocyte acetylcholinesterase[68] and the much smaller glycosphingolipid ganglioside GM1[69] are illustrated in Figure 5. To create synthetic cell surface receptors that are similar in size to ganglioside GM1, we have synthesized $N$-alkyl-cholesterylamines linked to a variety of small protein-binding motifs including fluorophores, $[57,61]$ peptides, [62] biotin,[60] and metal chelators.[70] Representative examples of fluorescent (1)[71] and metal-chelating (2)[70] derivatives of $\mathrm{N}$-alkyl-cholesterylamine are shown adjacent to the structure of ganglioside GM1 in Figure 5. Structurally similar cholesterylamines-linked to


the NTA head group of $\mathbf{2}$ exhibit receptor-like properties, enabling synthetic receptormediated endocytosis of antibodies and other proteins, including streptavidin and oligohistidine-tagged proteins that bind to these small head groups on cell surfaces.[57, 60$62,70]$ To illustrate the subcellular distribution and receptor-like activity of green fluorescent 1 in a suspension cell line, confocal laser scanning micrographs of human Jurkat cells treated with this compound followed by addition of a red fluorescent antifluorescein antibody at two time points are shown in Figure 6. These images show the localization of 1 on cell surfaces and in early endosomes, and time-dependent endocytic cellular uptake of this IgG dependent on treatment of cells with $\mathbf{1 .}$

The structure of the linker region and head group of cholesterylamine-derived synthetic receptors affects the ability of these compounds to bind cell surfaces, partition between the plasma membrane and early/recycling endosomes, and promote the uptake of impermeable ligands.[61] Correspondingly, treatment of cells with optimized synthetic receptors can enhance the uptake of proteins and other ligands by over 100-fold as quantified by flow cytometry.[61, 62] Ligands internalized in this way are delivered to late endosomes and lysosomes as evidenced by colocalization of fluorescent derivatives with EGFP-lgp120[61] or DiI-LDL.[72] Additionally, optimized synthetic receptors exhibit recycling half-lives of approximately $3 \mathrm{~min}$ at $37^{\circ} \mathrm{C}$ in living Jurkat lymphocytes.[61] This value is similar to the recycling kinetics of free cholesterol,[44] $\mathrm{C}_{6}-\mathrm{NBD}$ sphingomyelin,[73] and the LDL receptor[12] in other mammalian cell lines. 


\subsection{A synthetic Fc receptor}

Cholesterylamines have been shown to engage major endocytic membrane trafficking pathways occupied by many natural cell surface receptors. To probe the ability of these compounds to mimic natural $\mathrm{Fc}$ receptors $(\mathrm{FcR})$ such as GPI-linked human Fc $\gamma$ RIIIB (CD16),[9] our laboratory previously synthesized a derivative of the FcIII cyclic peptide, [74] a compound with high affinity and specificity $\left(\mathrm{K}_{\mathrm{i}}=25 \mathrm{nM}\right)$ for the $\mathrm{Fc}$ region of human $\mathrm{IgG}$, linked to a close analogue of cholesterylamine, $3 \beta$-amino-5a-cholestane (dihydrocholesterylamine).[72] The structure of a minimalistic synthetic Fc receptor (sFcR) and a model of this $\mathrm{sFcR}$ bound to the $\mathrm{Fc}$ region of human $\mathrm{IgG}$ are shown in Figure 7 (panels A-B). Human Jurkat lymphocytes do not express FcRs, and treatment of this cell line with fluorescent human IgG alone does not result in appreciable uptake of the antibody (Figure 7, panel C). However, Jurkat cells treated with the sFcR and fluorescent human IgG showed dose-dependent uptake of this fluorescent antibody (Figure 7, panel D). When these cells were compared with human THP-1 cells that express the natural FcRs Fc $\gamma$ RI and Fc $\gamma$ RII, Jurkat cells treated with one micromolar $\mathrm{sFcR}$ revealed greater uptake of human $\operatorname{IgG}$ (Figure 7, panel E).[72]

The $\mathrm{sFcR}$ rapidly inserted into and readily effluxed from cellular plasma membranes. Comparison with fluorescent bead standards and analysis by flow cytometry revealed that treatment of Jurkat cells with one micromolar sFcR for 1 hour installed about $6.2 \times 10^{5}$ molecules of $\mathrm{sFcR}$ per cell surface. Another major population of this compound resided in early/recycling endosomes, and rapid cycling between these subcellular locations was observed.[72] Under these conditions, the abundance of $\mathrm{sFcR}$ on Jurkat cell surfaces was substantially higher than the natural Fc receptors Fc $\gamma$ RI $\left(\sim 1.1 \times 10^{4} /\right.$ cell $)$ and Fc $\gamma$ RII $(\sim 3 \times$ $10^{4} /$ cell) found on THP-1 monocyte cells. However, treatment of Jurkat cells with $\mathrm{sFcR}$ followed by a single wash with media resulted in rapid shedding of this compound from cell surfaces with a half-life of 0.6 hours. Based on recent studies of cholesterylamines as substrates for reverse cholesterol transport,[71] shedding of the sFcR from cells likely involves this natural mechanism of cholesterol efflux.

In some autoimmune diseases, circulating autoreactive antibodies cause tissue damage and inflammation. As a consequence, it has been proposed that $\mathrm{sFcRs}$ may have therapeutic utility by promoting the cellular uptake and lysosomal degradation of human IgG in vivo. [72] In this novel therapeutic approach, injection of $\mathrm{sFcRs}$ might enable these compounds to insert into plasma membranes of diverse mammalian cells and remove circulating $\mathrm{IgG}$ from the extracellular environment to reduce the concentration of these ligands. To support this idea, studies of a simple cell culture model showed that addition of the $\mathrm{SFcR}$ (Figure 7) to media containing Jurkat lymphocyte cells depletes extracellular IgG as a consequence of synthetic receptor-mediated endocytosis.[72] This approach is conceptually similar to the effective but costly clinical treatment of autoimmune disease with intravenous immunoglobulin-G (IVIG), which promotes the catabolism of antibodies in vivo including pathogenic IgG.[75] Potential therapeutic applications of sFcRs are worthy of further exploration because IVIG is beneficial for treating a number of autoimmune disorders including multiple sclerosis, myasthenia gravis, pemphigus, Wegener's granulomatosis, Churg-Strauss syndrome, and chronic inflammatory demyelinating polyneuropathy, among other diseases. Although the development of synthetic cell surface receptors as agents for depleting endogenous ligands is an intriguing new concept, additional preclinical studies are necessary to validate this approach in vivo.

\subsection{A synthetic vancomycin receptor}

To promote receptor-mediated delivery, a wide variety of drugs and probes have been linked to ligands of natural cell surface receptors. These ligands include LDL, transferrin, folate, 
vitamin B12, and many others.[76] By coupling drugs to these ligands, cells expressing cognate receptors accumulate these drug-ligand complexes in late endosomes and lysosomes. Hydrolysis of functional groups or cleavage of disulfides linking drugs to ligands can release therapeutic agents. This approach has also been used to target receptors involved in receptor-mediated transcytosis to access natural pathways for delivery of nutrients across membranes such as the blood-brain barrier.[77]

To explore the potential utility of synthetic receptor-mediated drug delivery, termed synthetic receptor targeting, our laboratory designed[78] a cholesterylamine linked to the peptide sequence D-Phe-D-Ala. This dipeptide binds[79] the glycopeptide antibiotic vancomycin, a drug of last resort against gram positive pathogens such as methicillinresistant Staphylococcus aureus.[80] As shown in Figure 8 (panel A), this synthetic vancomycin receptor (sVancoR) was proposed to bind cellular plasma membranes, project the vancomycin-binding motif from cell surfaces, and promote endocytic delivery of vancomycin into mammalian cells. Treatment of normal mammalian cells with sVancoR and the vancomycin ligand was proposed to deliver this ligand into lysosomes, where the antibiotic would be degraded. In contrast, this delivery of vancomycin into mammalian cells infected with the gram-positive intracellular pathogen Listeria monocytogenes was hypothesized to release vancomycin from endosomes. Expression of the membrane-lytic protein listeriolysin $\mathrm{O}$ (LLO)[81, 82] by L. monocytogenes was proposed to trigger release of the antibiotic because LLO enables this pathogen to escape from phagosomes and enter the cytoplasm.[83] Consistent with this hypothesis, sVancoR was shown by confocal laser scanning microscopy of normal J-774 mouse macrophage cells to promote endocytosis of a fluorescent conjugate of vancomycin, resulting in its encapsulation in late endosomes/ lysosomes (Figure 8, panel B). However, under the same conditions, in cells infected with $L$. monocytogenes, fluorescent vancomycin was observed to escape from endosomes and diffuse throughout the cytosol and nucleus (Figure 8, panel C).

In human HeLa cells infected with L. monocytogenes, treatment with vancomycin and sVancoR eradicated this intracellular pathogen (Figure 8, panel D). Moreover, sVancoR and vancomycin rescued HeLa cells from the lethal effects of this pathogen (Figure 8, panel E). Control compounds that do not bind vancomycin or that exhibit lower affinity for cellular plasma membranes did not show these beneficial effects, further supporting the hypothesis that sVancoR does not simply permeabilize cells, but rather binds vancomycin on cell surfaces and promotes endocytosis by mimicking the trafficking of natural cell surface receptors.[78]

Studies of sVancoR in vivo in mice examined the ability of this compound to affect the tissue distribution of a fluorescent vancomycin conjugate.[78] In these experiments, mice were injected intraperitoneally with the fluorescent vancomycin alone or the fluorescent vancomycin and the sVancoR at $50 \mathrm{mg} / \mathrm{kg}$. After eight hours, the tissues shown in Figure 8 (panel F) were harvested, single cell populations were prepared, and cellular fluorescence was analyzed by flow cytometry. These studies revealed that sVancoR substantially enhances the accumulation of fluorescent vancomycin in a wide range of tissues, particularly in skeletal muscle, pancreas, spleen, liver and brain. The synthetic receptor-mediated accumulation of fluorescent vancomycin in the brain is of particular interest given that less than $2 \%$ of all drugs are capable of penetrating the blood-brain barrier. The brain studies of sVancoR analyzed all cells isolated from this organ by flow cytometry, and the distribution among different cell types within the brain was not determined. Consequently, more detailed studies are needed to determine the magnitude of delivery into different cell types. If cholesterylamine-derived synthetic receptors can be demonstrated to efficiently engage receptor-mediated transcytosis pathways into the CNS in vivo, this approach could provide important new tools for accessing this poorly accessible tissue. 


\subsection{Related synthetic compounds that escape from endosomes}

Receptor-mediated endocytosis is a highly efficient cellular uptake mechanism. Ligands internalized through this process are encapsulated in membrane-sealed endosomes and are typically shuttled into lysosomes containing highly hydrolytic enzymes. As a consequence, many therapeutics and probes internalized through this route remain trapped in these compartments and do not reach the cytosol or nucleus in high concentrations. Although many viruses enter cells through endocytic mechanisms by mimicking the uptake of natural ligands, these pathogens have evolved to avoid degradation in lysosomes. For example, SV40 accesses alternative membrane trafficking pathways to bypass lysosomes, enveloped viruses such as influenza escape from endosomes by fusion of viral envelopes with endosomal membranes,[84] and non-enveloped viruses produce peptides or proteins that disrupt membranes at low pH.[33] Previously reported studies of endosome disruptive peptides, proteins, and polymers have extensively focused on $\mathrm{pH}$-dependent fragments and mimics of hydrophobic/acidic fusogenic proteins of enveloped viruses such as influenza. Protonation of glutamic acids and other acidic residues[85] of these peptides in endosomes enhances hydrophobicity to promote interaction with and destabilization of membranes.[86] Alternatively, weakly basic endosomolytic monoamines that become increasingly protonated in endosomes, as well as $\mathrm{pH}$-labile covalent bonds integrated into delivery systems, have also been used to disrupt the structure and function of endosomes. These and related approaches have been recently reviewed.[87-89]

We have investigated the delivery of synthetic membrane-active peptides into early endosomes using cholesterylamines. The incorporation of glutamic acid residues proximal to $N$-alkyl-3ß-cholesterylamine can be used to preferentially localize these compounds in early endosomes compared with the plasma membrane of living cells, providing a unique platform for targeting molecules to these intracellular compartments.[90] By linking a membranelytic peptide termed PC-4[91] to an $N$-alkyl-cholesterylamine, we demonstrated that a disulfide-linked fluorescent probe can be released from early endosomes into the cytoplasm and nucleus of living mammalian cells.[90] This novel two-component delivery system employed the endosome disruptor (3) shown in Figure 9 (panel A). This cholesterylaminelinked endosome disruptor (3) was proposed to trigger cleavage of the disulfide of the fluorescent cholesterylamine $\mathbf{4}$ and release fluorophore 5 (Figure 9, panel B) into the cytosol and nucleus of animal cells through the mechanism shown in Figure 9 (Panel C). This mechanism is based on the observation that, like the extracellular environment, endosomes are oxidizing[92] and disruption of these compartments could allow reduced glutathione (GSH), present at high concentrations in the cytosol, to cleave disulfides targeted to the lumen of these organelles.

Confocal laser scanning microscopy of living Jurkat lymphocyte cells treated with the cholesterylamine-linked fluorescent disulfide (4) revealed that this compound accumulates to high levels in early endosomes (Figure 9, panel D). In contrast, when the cholesterylamine-linked endosome disruptor (3) is coadministered with $\mathbf{4}$, the disulfide of $\mathbf{4}$ is cleaved within 14 hours, and the fluorescence of $\mathbf{5}$ can be observed throughout the cytoplasm and nucleus (Figure 9, panel E). This method for disruption of early endosomes appears to be effective in a wide variety of mammalian cells. In Jurkat lymphocytes, the efficacy of endosome disruption by 4 was quantified by flow cytometry as $\mathrm{EC}_{50}=1.6 \mu \mathrm{M}$. This value was obtained by measuring the enhancement of fluorescence associated with release of the $\mathrm{pH}$-sensitive carboxyfluorescein group of $\mathbf{5}$ from acidic endosomes into the neutral cytosol. Toxicity of $\mathbf{3}$ to Jurkat lymphocytes after treatment for 48 hours required higher concentrations $\left(\mathrm{IC}_{50}=9.0 \mu \mathrm{M}\right.$ ), indicating useful selectivity of release of the probe over toxic effects to cells. This selectivity likely relates to the $\mathrm{pH}$-dependent membrane-lytic activity of the PC4 peptide[91] and effective targeting of this peptide to early endosomes by 
the linked cholesterylamine. Although a number of synthetic agents have been shown to disrupt endosomes of mammalian cells, [87-89] the ability of cholesterylamine to target less hydrolytic early/recycling endosomes and release cargo from these compartments may be beneficial for the delivery of sensitive materials such as nucleic acids and proteins into the cytosol.

\section{Other approaches}

A number of diverse methods for cell surface engineering have been reported, and a comprehensive review on this topic was recently published.[93] Methods that mimic natural cell surface receptors include a technique termed "protein painting"[94-97] in which proteins linked to glycoinositol phospholipids are added to cells and become incorporated into cellular plasma membranes. This approach has been used to study cellular signaling, plasma membrane organization, and recognition of modified cell surfaces by the immune system. Related recombinant GPI-linked proteins have been used to protect vasculature from immune responses to transplanted organs.[98] Because GPI-linked proteins undergo clathrin-independent endocytosis, Jurkat lymphocytes treated with a GPI-linked variant of the immunoglobulin Fc receptor Fc $\gamma$ RIII will endocytose ligands that bind this receptor.[99] Single-chain antibodies covalently linked to lipids have been used to construct related cell surface receptors.[96] Similarly, palmitoylated Protein A and Protein G can be incorporated into cellular plasma membranes and have been used to create artificial cell surface receptors that bind antibodies or other proteins fused to antibody Fc regions.[100-103] Similarly, recombinant diphtheria toxin $\mathrm{T}$ domain has been used to anchor the IgG-binding protein $\mathrm{ZZ}$ to cellular plasma membranes.[104, 105] Using synthetic glycopolymers, Bertozzi and coworkers created mimics of cell surface mucins that recognize glycan-binding proteins and become internalized into early endosomes.[39] This chemical approach was used to study cell surface phenomena with a level of molecular control that cannot be obtained using conventional biological approaches. Other polymers have also been used to display binding groups from cell surfaces,[106] and promote the uptake of impermeable ligands.[107] A driving force behind some of these strategies has been to enhance the immunogenicity of treated tumor cells as an approach to create potential cancer vaccines. Coating of cells with receptor-like proteins has also been used as a strategy to promote cell-cell interactions such as targeting of stem cells to sites of inflammation or injury.

\section{Conclusions and perspectives}

The chemical biology approach of mimicry of membrane-associated biomolecules such as cholesterol can be used to design prosthetic molecules that become seamlessly incorporated into cellular plasma membranes. Although many membrane-associated biomolecules including proteins, lipids, and carbohydrates[108, 109] all have the potential to be mimicked in this way, our laboratory has focused on constructing synthetic cell surface receptors from derivatives of cholesterylamine, a cholesterol analogue easily prepared from cholesterol.[56] These mimics of cholesterol are a particularly useful platform for these studies because they can be readily linked to ligand binding motifs, many of these compounds become selectively inserted into the exofacial leaflet of plasma membranes of living mammalian cells, and these compounds can rapidly cycle between the cell surface and early/recycling endosomes. Because cholesterylamines can be designed to not only deliver ligands into endosomes, but can also be linked to membrane-lytic peptides that disrupt these compartments and release linked cargo into the cytoplasm and nucleus,[90] this platform may be useful for the development of improved methods for intracellular delivery of a wide variety of poorly permeable agents. 
Therapeutic applications of synthetic cell surface receptors are at an early stage of development. Treatment of cancer cells with receptor-like molecules has been proposed as a strategy to enhance immunogenicity for construction of cancer vaccines [96, 104] and to target stem cells to sites of inflammation and injury.[100,102] Another intriguing new concept involves the potential use of synthetic cell surface receptors to deplete endogenous extracellular ligands.[72] Towards this end, a synthetic $\mathrm{Fc}$ receptor $(\mathrm{sFcR})$ that binds human $\mathrm{IgG}$ was used to generate preliminary in vitro proof-of-concept that this compound depletes IgG from cell culture media by promoting its endocytic uptake and lysosomal degradation. If this strategy can be validated in vivo, the depletion of circulating pathogenic $\mathrm{IgG}$, responsible for some autoimmune diseases, might be another useful application of this approach.

As a new strategy for drug delivery, synthetic receptor-mediated cellular uptake of the cellimpermeable antibiotic vancomycin has been examined.[78] Cells treated with both a cholesterylamine linked to the vancomycin-binding motif D-Phe-D-Ala and vancomycin as a ligand eradicated intracellular L. monocytogenes in infected HeLa cells, rescued these mammalian host cells from lethal effects of this pathogen, and enhanced the tissue distribution of a fluorescent derivative of vancomycin in mice in vivo. Although this approach is promising, vancomycin is known to have intrinsic liabilities associated with toxicity,[80] and other cell-permeable antibiotics are effective against intracellular pathogenic bacteria. Consequently, the delivery of vancomycin using this approach may be of limited clinical utility. However, this proof-of-concept that a synthetic receptor that binds vancomycin can be used to extend the range of its intracellular antibiotic activity to the cytoplasm of mammalian cells should encourage studies of other drug delivery systems based on this approach.

Synthetic receptor-mediated endocytosis of vancomycin by mammalian cells infected with L. monocytogenes resulted in escape of this antibiotic from endosomes into the cytoplasm and nucleus. This change in subcellular distribution in the presence of this pathogen is likely due to expression of the bacterial protein LLO, which enables this pathogen to escape entrapment in intracellular membrane-sealed phagosomes. [81-83] Based on this observation, membrane-lytic peptides linked to cholesterylamines have been investigated. These studies led to the discovery that delivery of the membrane-lytic peptide PC4 into early/recycling endosomes by a cholesterylamine could effectively release a disulfide-linked fluorophore into the cytoplasm and nucleus of a variety of mammalian cell lines.[90] Further development of this strategy could focus on improving the potency and efficacy of these endosome disruptive agents, establish the range of cargo sizes that can be released by these compounds, and work to overcome challenges in therapeutic delivery of biomolecules such as RNAi. The delivery of short interfering RNA (siRNA) with this approach is especially promising given that cholesterol-conjugated siRNAs can silence genes both in vitro and in vivo, particularly in the liver.[110-113] Examination of the biological consequences of endosome disruption may be useful for optimization of these compounds. For example, silica crystals and aluminum salts have been shown to disrupt lysosomes and release cathepsin B, activating inflammasomes that function as sensors of lysosomal damage.[114] The development of potent synthetic compounds that efficiently release cargo by targeting and selectively disrupting early/recycling endosomes without triggering inflammasomes or other detrimental biological responses could provide important new tools for the delivery of therapeutics and probes.

\section{Acknowledgments}

We thank the NIH (R01 CA83831) for financial support. DH thanks the American Chemical Society Division of Medicinal Chemistry for a predoctoral fellowship. 


\section{References}

1. McMahon HT, Boucrot E. Molecular mechanism and physiological functions of clathrin-mediated endocytosis. Nat Rev Mol Cell biol. 2011; 12:517-533. [PubMed: 21779028]

2. Doherty GJ, McMahon HT. Mechanisms of endocytosis. Annual review of biochemistry. 2009; 78:857-902.

3. Sandvig K, Pust S, Skotland T, van Deurs B. Clathrin-independent endocytosis: mechanisms and function. Current opinion in cell biology. 2011; 23:413-420. [PubMed: 21466956]

4. Manes S, del Real G, Martinez AC. Pathogens: raft hijackers. Nat Rev Immunol. 2003; 3:557-568. [PubMed: 12876558]

5. Stehle T, Gamblin SJ, Yan Y, Harrison SC. The structure of simian virus 40 refined at $3.1 \mathrm{~A}$ resolution. Structure. 1996; 4:165-182. [PubMed: 8805523]

6. Neu U, Woellner K, Gauglitz G, Stehle T. Structural basis of GM1 ganglioside recognition by simian virus 40. Proc Natl Acad Sci USA. 2008; 105:5219-5224. [PubMed: 18353982]

7. Rudenko G, Henry L, Henderson K, Ichtchenko K, Brown MS, Goldstein JL, Deisenhofer J. Structure of the LDL receptor extracellular domain at endosomal pH. Science. 2002; 298:23532358. [PubMed: 12459547]

8. Cheng Y, Zak O, Aisen P, Harrison SC, Walz T. Structure of the human transferrin receptortransferrin complex. Cell. 2004; 116:565-576. [PubMed: 14980223]

9. Radaev S, Motyka S, Fridman WH, Sautes-Fridman C, Sun PD. The structure of a human type III Fcgamma receptor in complex with Fc. J Biol Chem. 2001; 276:16469-16477. [PubMed: 11297532]

10. Orlova EV, Sherman MB, Chiu W, Mowri H, Smith LC, Gotto AM Jr. Three-dimensional structure of low density lipoproteins by electron cryomicroscopy. Proc Natl Acad Sci USA. 1999; 96:8420-8425. [PubMed: 10411890]

11. Goldstein JL, Brown MS, Anderson RG, Russell DW, Schneider WJ. Receptor-mediated endocytosis: concepts emerging from the LDL receptor system. Annu Rev Cell Biol. 1985; 1:139. [PubMed: 2881559]

12. Brown MS, Goldstein JL. A receptor-mediated pathway for cholesterol homeostasis. Angew Chem Int Ed Engl. 1986; 25:583-602.

13. Lakadamyali M, Rust MJ, Zhuang XW. Ligands for clathrin-mediated endocytosis are differentially sorted into distinct populations of early endosomes. Cell. 2006; 124:997-1009. [PubMed: 16530046]

14. Jeon H, Blacklow SC. Structure and physiologic function of the low-density lipoprotein receptor. Annual review of biochemistry. 2005; 74:535-562.

15. Keyel PA, Mishra SK, Roth R, Heuser JE, Watkins SC, Traub LM. A single common portal for clathrin-mediated endocytosis of distinct cargo governed by cargo-selective adaptors. Mol Biol Cell. 2006; 17:4300-4317. [PubMed: 16870701]

16. Garcia CK, Wilund K, Arca M, Zuliani G, Fellin R, Maioli M, Calandra S, Bertolini S, Cossu F, Grishin N, Barnes R, Cohen JC, Hobbs HH. Autosomal recessive hypercholesterolemia caused by mutations in a putative LDL receptor adaptor protein. Science. 2001; 292:1394-1398. [PubMed: 11326085]

17. Maxfield FR, McGraw TE. Endocytic recycling. Nat Rev Mol Cell Biol. 2004; 5:121-132. [PubMed: 15040445]

18. Grant BD, Donaldson JG. Pathways and mechanisms of endocytic recycling. Nat Rev Mol Cell Biol. 2009; 10:597-608. [PubMed: 19696797]

19. Beglova N, Blacklow SC. The LDL receptor: how acid pulls the trigger. Trends Biochem Sci. 2005; 30:309-317. [PubMed: 15950875]

20. Stephan ZF, Yurachek EC. Rapid fluorometric assay of LDL receptor activity by DiI-labeled LDL. J Lipid Res. 1993; 34:325-330. [PubMed: 8381454]

21. Wang Q, Villeneuve G, Wang ZX. Control of epidermal growth factor receptor endocytosis by receptor dimerization, rather than receptor kinase activation. EMBO Rep. 2005; 6:942-948. [PubMed: 16113650] 
22. Hilgenbrink AR, Low PS. Folate receptor-mediated drug targeting: from therapeutics to diagnostics. J Pharm Sci. 2005; 94:2135-2146. [PubMed: 16136558]

23. Sabharanjak S, Mayor S. Folate receptor endocytosis and trafficking. Adv Drug Deliv Rev. 2004; 56:1099-1109. [PubMed: 15094209]

24. Meknache N, Jonsson F, Laurent J, Guinnepain MT, Daeron M. Human basophils express the glycosylphosphatidylinositol-anchored low-affinity IgG receptor FcgammaRIIIB (CD16B). J Immunol. 2009; 182:2542-2550. [PubMed: 19201911]

25. Mayor S, Riezman H. Sorting GPI-anchored proteins. Nat Rev Mol Cell Biol. 2004; 5:110-120. [PubMed: 15040444]

26. Merritt EA, Kuhn P, Sarfaty S, Erbe JL, Holmes RK, Hol WG. The 1.25 A resolution refinement of the cholera toxin B-pentamer: evidence of peptide backbone strain at the receptor-binding site. $\mathrm{J}$ Mol Biol. 1998; 282:1043-1059. [PubMed: 9753553]

27. Smith DC, Lord JM, Roberts LM, Johannes L. Glycosphingolipids as toxin receptors. Semin Cell Dev Biol. 2004; 15:397-408. [PubMed: 15207830]

28. Ewers H, Helenius A. Lipid-mediated endocytosis. Cold Spring Harb Perspect Biol. 2011; 3:a004721. [PubMed: 21576253]

29. Mercer J, Schelhaas M, Helenius A. Virus entry by endocytosis. Annual review of biochemistry. 2010; 79:803-833.

30. Lundmark R, Doherty GJ, Howes MT, Cortese K, Vallis Y, Parton RG, McMahon HT. The GTPase-Activating Protein GRAF1 Regulates the CLIC/GEEC Endocytic Pathway. Curr Biol. 2008; 18:1802-1808. [PubMed: 19036340]

31. Howes MT, Mayor S, Parton RG. Molecules, mechanisms, and cellular roles of clathrinindependent endocytosis. Current opinion in cell biology. 2010; 22:519-527. [PubMed: 20439156]

32. Kirkham M, Fujita A, Chadda R, Nixon SJ, Kurzchalia TV, Sharma DK, Pagano RE, Hancock JF, Mayor S, Parton RG. Ultrastructural identification of uncoated caveolin-independent early endocytic vehicles. The Journal of cell biology. 2005; 168:465-476. [PubMed: 15668297]

33. Smith AE, Helenius A. How viruses enter animal cells. Science. 2004; 304:237-242. [PubMed: 15073366]

34. Mann RK, Beachy PA. Cholesterol modification of proteins. Biochim Biophys Acta. 2000; 1529:188-202. [PubMed: 11111088]

35. Levental I, Grzybek M, Simons K. Greasing Their Way: Lipid Modifications Determine Protein Association with Membrane Rafts. Biochemistry. 2010; 49:6305-6316. [PubMed: 20583817]

36. Mesmin B, Maxfield FR. Intracellular sterol dynamics. Biochim Biophys Acta. 2009; 1791:636645. [PubMed: 19286471]

37. Marks DL, Bittman R, Pagano RE. Use of Bodipy-labeled sphingolipid and cholesterol analogs to examine membrane microdomains in cells. Histochem Cell Biol. 2008; 130:819-832. [PubMed: 18820942]

38. Marks DL, Singh RD, Choudhury A, Wheatley CL, Pagano RE. Use of fluorescent sphingolipid analogs to study lipid transport along the endocytic pathway. Methods. 2005; 36:186-195.

[PubMed: 15905102]

39. Rabuka D, Forstner MB, Groves JT, Bertozzi CR. Noncovalent cell surface engineering: incorporation of bioactive synthetic glycopolymers into cellular membranes. J Am Chem Soc. 2008; 130:5947-5953. [PubMed: 18402449]

40. Wollack JW, Zeliadt NA, Mullen DG, Amundson G, Geier S, Falkum S, Wattenberg EV, Barany G, Distefano MD. Multifunctional prenylated peptides for live cell analysis. J Am Chem Soc. 2009; 131:7293-7303. [PubMed: 19425596]

41. Dafik L, Kalsani V, Leung AK, Kumar K. Fluorinated lipid constructs permit facile passage of molecular cargo into living cells. J Am Chem Soc. 2009; 131:12091-12093. [PubMed: 19673473]

42. Andreev OA, Engelman DM, Reshetnyak YK. pH-sensitive membrane peptides (pHLIPs) as a novel class of delivery agents. Mol Memb Biol. 2010; 27:341-352.

43. Maxfield FR, van Meer G. Cholesterol, the central lipid of mammalian cells. Current opinion in cell biology. 2010; 22:422-429. [PubMed: 20627678] 
44. Maxfield FR, Mondal M. Sterol and lipid trafficking in mammalian cells. Biochem Soc Trans. 2006; 34:335-339. [PubMed: 16709155]

45. Petrache HI, Dodd SW, Brown MF. Area per lipid and acyl length distributions in fluid phosphatidylcholines determined by (2)H NMR spectroscopy. Biophys J. 2000; 79:3172-3192. [PubMed: 11106622]

46. Steck TL, Ye J, Lange Y. Probing red cell membrane cholesterol movement with cyclodextrin. Biophys J. 2002; 83:2118-2125. [PubMed: 12324429]

47. Hao M, Lin SX, Karylowski OJ, Wustner D, McGraw TE, Maxfield FR. Vesicular and nonvesicular sterol transport in living cells. The endocytic recycling compartment is a major sterol storage organelle. J Biol Chem. 2002; 277:609-617. [PubMed: 11682487]

48. Wustner D, Solanko L, Sokol E, Garvik O, Li ZG, Bittman R, Korte T, Herrmann A. Quantitative assessment of sterol traffic in living cells by dual labeling with dehydroergosterol and BODIPYcholesterol. Chem Phys Lipids. 2011; 164:221-235. [PubMed: 21291873]

49. Holtta-Vuori M, Uronen RL, Repakova J, Salonen E, Vattulainen I, Panula P, Li ZG, Bittman R, Ikonen E. BODIPY-Cholesterol: A New Tool to Visualize Sterol Trafficking in Living Cells and Organisms. Traffic. 2008; 9:1839-1849. [PubMed: 18647169]

50. Sankaranarayanan S, Kellner-Weibel G, de la Llera-Moya M, Phillips MC, Asztalos BF, Bittman R, Rothblat GH. A sensitive assay for ABCA1-mediated cholesterol efflux using BODIPYcholesterol. J Lipid Res. 2011; 52:2332-2340. [PubMed: 21957199]

51. Ishii H, Shimanouchi T, Umakoshi H, Walde P, Kuboi R. Analysis of the 22-NBD-cholesterol transfer between liposome membranes and its relation to the intermembrane exchange of 25hydroxycholesterol. Colloids Surf B. 2010; 77:117-121.

52. Mukherjee S, Zha XH, Tabas I, Maxfield FR. Cholesterol distribution in living cells: Fluorescence imaging using dehydroergosterol as a fluorescent cholesterol analog. Biophys J. 1998; 75:19151925. [PubMed: 9746532]

53. Maxfield FR, Wustner D. Analysis of cholesterol trafficking with fluorescent probes. Methods Cell Biol. 2012; 108:367-393. [PubMed: 22325611]

54. Gimpl G, Gehrig-Burger K. Cholesterol reporter molecules. Biosci Rep. 2007; 27:335-358. [PubMed: 17668316]

55. Kan CC, Yan J, Bittman R. Rates of spontaneous exchange of synthetic radiolabeled sterols between lipid vesicles. Biochemistry. 1992; 31:1866-1874. [PubMed: 1737039]

56. Sun Q, Cai S, Peterson BR. Practical synthesis of 3beta-amino-5-cholestene and related 3betahalides involving i-steroid and retro-i-steroid rearrangements. Org Lett. 2009; 11:567-570. [PubMed: 19115840]

57. Hussey SL, He E, Peterson BR. A synthetic membrane-anchored antigen efficiently promotes uptake of antifluorescein antibodies and associated protein a by mammalian cells. J Am Chem Soc. 2001; 123:12712-12713. [PubMed: 11741450]

58. Hussey SL, He E, Peterson BR. Synthesis of chimeric 7 alpha-substituted estradiol derivatives linked to cholesterol and cholesterylamine. Org Lett. 2002; 4:415-418. [PubMed: 11820893]

59. Hussey SL, Muddana SS, Peterson BR. Synthesis of a beta-estradiol-biotin chimera that potently heterodimerizes estrogen receptor and streptavidin proteins in a yeast three-hybrid system. $\mathrm{J}$ Am Chem Soc. 2003; 125:3692-3693. [PubMed: 12656587]

60. Hussey SL, Peterson BR. Efficient delivery of streptavidin to mammalian cells: clathrin-mediated endocytosis regulated by a synthetic ligand. J Am Chem Soc. 2002; 124:6265-6273. [PubMed: 12033853]

61. Boonyarattanakalin S, Martin SE, Dykstra SA, Peterson BR. Synthetic mimics of small mammalian cell surface receptors. J Am Chem Soc. 2004; 126:16379-16386. [PubMed: 15600339]

62. Martin SE, Peterson BR. Non-natural cell surface receptors: synthetic peptides capped with Ncholesterylglycine efficiently deliver proteins into mammalian cells. Bioconjugate Chem. 2003; 14:67-74.

63. Peterson BR. Synthetic mimics of mammalian cell surface receptors: prosthetic molecules that augment living cells. Org Biomol Chem. 2005; 3:3607-3612. [PubMed: 16211095] 
64. Lonnfors M, Engberg O, Peterson BR, Slotte JP. Interaction of 3beta-Amino-5-cholestene with Phospholipids in Binary and Ternary Bilayer Membranes. Langmuir. 2012; 28:648-655. [PubMed: 22128897]

65. Linsel-Nitschke P, Tall AR. HDL as a target in the treatment of atherosclerotic cardiovascular disease. Nat Rev Drug Disc. 2005; 4:193-205.

66. Mottram LF, Boonyarattanakalin S, Kovel RE, Peterson BR. The Pennsylvania Green Fluorophore: A Hybrid of Oregon Green and Tokyo Green for the Construction of Hydrophobic and pH-Insensitive Molecular Probes. Org Lett. 2006; 8:581-584. [PubMed: 16468716]

67. Yoshimori T, Yamamoto A, Moriyama Y, Futai M, Tashiro Y. Bafilomycin A1, a specific inhibitor of vacuolar-type $\mathrm{H}(+)$-ATPase, inhibits acidification and protein degradation in lysosomes of cultured cells. J Biol Chem. 1991; 266:17707-17712. [PubMed: 1832676]

68. Deeg MA, Humphrey DR, Yang SH, Ferguson TR, Reinhold VN, Rosenberry TL. Glycan components in the glycoinositol phospholipid anchor of human erythrocyte acetylcholinesterase. Novel fragments produced by trifluoroacetic acid. J Biol Chem. 1992; 267:18573-18580. [PubMed: 1388156]

69. Wennekes T, van den Berg RJ, Boot RG, van der Marel GA, Overkleeft HS, Aerts JM. Glycosphingolipids--nature, function, and pharmacological modulation. Angew Chem Int Ed. 2009; 48:8848-8869.

70. Boonyarattanakalin S, Athavankar S, Sun Q, Peterson BR. Synthesis of an artificial cell surface receptor that enables oligohistidine affinity tags to function as metal-dependent cell-penetrating peptides. J Am Chem Soc. 2006; 128:386-387. [PubMed: 16402806]

71. Zhang J, Cai S, Peterson BR, Kris-Etherton PM, Heuvel JP. Development of a cell-based, highthroughput screening assay for cholesterol efflux using a fluorescent mimic of cholesterol. Assay Drug Dev Tech. 2011; 9:136-146.

72. Boonyarattanakalin S, Martin SE, Sun Q, Peterson BR. A Synthetic Mimic of Human Fc Receptors: Defined Chemical Modification of Cell Surfaces Enables Efficient Endocytic Uptake of Human Immunoglobulin-G. J Am Chem Soc. 2006; 128:11463-11470. [PubMed: 16939269]

73. Hao M, Maxfield FR. Characterization of rapid membrane internalization and recycling. J Biol Chem. 2000; 275:15279-15286. [PubMed: 10809763]

74. DeLano WL, Ultsch MH, de Vos AM, Wells JA. Convergent solutions to binding at a proteinprotein interface. Science. 2000; 287:1279-1283. [PubMed: 10678837]

75. Looney RJ, Huggins J. Use of intravenous immunoglobulin G (IVIG). Best Pract Res Cl Ha. 2006; 19:3-25.

76. Bareford LM, Swaan PW. Endocytic mechanisms for targeted drug delivery. Adv Drug Del Rev. 2007; 59:748-758.

77. Pardridge WM. Biopharmaceutical drug targeting to the brain. J Drug Target. 2010; 18:157-167. [PubMed: 20064077]

78. Boonyarattanakalin S, Hu J, Dykstra-Rummel SA, August A, Peterson BR. Endocytic delivery of vancomycin mediated by a synthetic cell surface receptor: rescue of bacterially infected mammalian cells and tissue targeting in vivo. J Am Chem Soc. 2007; 129:268-269. [PubMed: 17212394]

79. Chu YH, Dunayevskiy YM, Kirby DP, Vouros P, Karger BL. Affinity capillary electrophoresis mass spectrometry for screening combinatorial libraries. J Am Chem Soc. 1996; 118:7827-7835.

80. Levine DP. Vancomycin: a history. Clin infect Dis. 2006; 42(Suppl 1):S5-S12. [PubMed: 16323120]

81. Kayal S, Charbit A. Listeriolysin O: a key protein of Listeria monocytogenes with multiple functions. FEMS Micro Rev. 2006; 30:514-529.

82. Schuerch DW, Wilson-Kubalek EM, Tweten RK. Molecular basis of listeriolysin O pH dependence. Proc Natl Acad Sci USA. 2005; 102:12537-12542. [PubMed: 16105950]

83. Gruenberg J, van der Goot FG. Mechanisms of pathogen entry through the endosomal compartments. Nat Rev Mol Cell Biol. 2006; 7:495-504. [PubMed: 16773132]

84. Lakadamyali M, Rust MJ, Zhuang X. Endocytosis of influenza viruses. Microbes Infect. 2004; 6:929-936. [PubMed: 15310470] 
85. Wang F, Qin L, Wong P, Gao J. Facile synthesis of tetrafluorotyrosine and its application in $\mathrm{pH}$ triggered membrane lysis. Org Lett. 2011; 13:236-239. [PubMed: 21142016]

86. Li W, Nicol F, Szoka FC Jr. GALA: a designed synthetic pH-responsive amphipathic peptide with applications in drug and gene delivery. Adv Drug Del Rev. 2004; 56:967-985.

87. Wolff JA, Rozema DB. Breaking the bonds: non-viral vectors become chemically dynamic. Mol Ther. 2008; 16:8-15. [PubMed: 17955026]

88. Nakase I, Kobayashi S, Futaki S. Endosome-disruptive peptides for improving cytosolic delivery of bioactive macromolecules. Biopolymers. 2010; 94:763-770. [PubMed: 20564044]

89. Varkouhi AK, Scholte M, Storm G, Haisma HJ. Endosomal escape pathways for delivery of biologicals. J Control Release. 2011; 151:220-228. [PubMed: 21078351]

90. Sun Q, Cai S, Peterson BR. Selective disruption of early/recycling endosomes: release of disulfidelinked cargo mediated by a N-alkyl-3beta-cholesterylamine-capped peptide. J Am Chem Soc. 2008; 130:10064-10065. [PubMed: 18613675]

91. Hirosue S, Weber T. pH-Dependent lytic peptides discovered by phage display. Biochemistry. 2006; 45:6476-6487. [PubMed: 16700558]

92. Austin CD, Wen X, Gazzard L, Nelson C, Scheller RH, Scales SJ. Oxidizing potential of endosomes and lysosomes limits intracellular cleavage of disulfide-based antibody-drug conjugates. Proc Natl Acad Sci USA. 2005; 102:17987-17992. [PubMed: 16322102]

93. Stephan MT, Irvine DJ. Enhancing cell therapies from the outside in: Cell surface engineering using synthetic nanomaterials. Nano Today. 2011; 6:309-325. [PubMed: 21826117]

94. Medof ME, Nagarajan S, Tykocinski ML. Cell-surface engineering with GPI-anchored proteins. Faseb J. 1996; 10:574-586. [PubMed: 8621057]

95. Premkumar DR, Fukuoka Y, Sevlever D, Brunschwig E, Rosenberry TL, Tykocinski ML, Medof ME. Properties of exogenously added GPI-anchored proteins following their incorporation into cells. J Cell Biochem. 2001; 82:234-245. [PubMed: 11527149]

96. de Kruif J, Tijmensen M, Goldsein J, Logtenberg T. Recombinant lipid-tagged antibody fragments as functional cell-surface receptors. Nat Med. 2000; 6:223-227. [PubMed: 10655115]

97. van den Berg CW, Cinek T, Hallett MB, Horejsi V, Morgan BP. Exogenous glycosyl phosphatidylinositol-anchored CD59 associates with kinases in membrane clusters on U937 cells and becomes $\mathrm{Ca}(2+)$-signaling competent. J Cell Biol. 1995; 131:669-677. [PubMed: 7593188]

98. Notohamiprodjo M, Djafarzadeh R, Mojaat A, von Luttichau I, Grone HJ, Nelson PJ. Generation of GPI-linked CCL5 based chemokine receptor antagonists for the suppression of acute vascular damage during allograft transplantation. Prot Eng Des Sel. 2006; 19:27-35.

99. Nagarajan S, Anderson M, Ahmed SN, Sell KW, Selvaraj P. Purification and optimization of functional reconstitution on the surface of leukemic cell lines of GPI-anchored Fc gamma receptor III. J Immunol Methods. 1995; 184:241-251. [PubMed: 7658026]

100. Ko IK, Kean TJ, Dennis JE. Targeting mesenchymal stem cells to activated endothelial cells. Biomaterials. 2009; 30:3702-3710. [PubMed: 19375791]

101. Kim SA, Peacock JS. The use of palmitate-conjugated protein A for coating cells with artificial receptors which facilitate intercellular interactions. J Immunol Meth. 1993; 158:57-65.

102. Dennis JE, Cohen N, Goldberg VM, Caplan AI. Targeted delivery of progenitor cells for cartilage repair. J Orthop Res. 2004; 22:735-741. [PubMed: 15183428]

103. Chen A, Zheng G, Tykocinski ML. Hierarchical costimulator thresholds for distinct immune responses: application of a novel two-step Fc fusion protein transfer method. J Immunol. 2000; 164:705-711. [PubMed: 10623813]

104. Nizard P, Chenal A, Beaumelle B, Fourcade A, Gillet D. Prolonged display or rapid internalization of the IgG-binding protein $\mathrm{ZZ}$ anchored to the surface of cells using the diphtheria toxin T domain. Protein Eng. 2001; 14:439-446. [PubMed: 11477224]

105. Nizard P, Liger D, Gaillard C, Gillet D. Anchoring antibodies to membranes using a diphtheria toxin T domain-ZZ fusion protein as a pH sensitive membrane anchor. FEBS letters. 1998; 433:83-88. [PubMed: 9738938]

106. Kamitani R, Niikura K, Okajima T, Matsuo Y, Ijiro K. Design of cell-surface-retained polymers for artificial ligand display. Chembiochem. 2009; 10:230-233. [PubMed: 19090520] 
107. Niikura K, Nambara K, Okajima T, Kamitani R, Aoki S, Matsuo Y, Ijiro K. Artificial polymeric receptors on the cell surface promote the efficient cellular uptake of quantum dots. Org Biomol Chem. 2011; 9:5787-5792. [PubMed: 21738911]

108. Campbell CT, Sampathkumar SG, Yarema KJ. Metabolic oligosaccharide engineering: perspectives, applications, and future directions. Molecular bioSystems. 2007; 3:187-194. [PubMed: 17308665]

109. Dube DH, Bertozzi CR. Metabolic oligosaccharide engineering as a tool for glycobiology. Curr Opin Chem Biol. 2003; 7:616-625. [PubMed: 14580567]

110. Wolfrum C, Shi S, Jayaprakash KN, Jayaraman M, Wang G, Pandey RK, Rajeev KG, Nakayama T, Charrise K, Ndungo EM, Zimmermann T, Koteliansky V, Manoharan M, Stoffel M.

Mechanisms and optimization of in vivo delivery of lipophilic siRNAs. Nat Biotechnol. 2007; 25:1149-1157. [PubMed: 17873866]

111. Lorenz C, Hadwiger P, John M, Vornlocher HP, Unverzagt C. Steroid and lipid conjugates of siRNAs to enhance cellular uptake and gene silencing in liver cells. Bioorg Med Chem Lett. 2004; 14:4975-4977. [PubMed: 15341962]

112. Siegwart DJ, Whitehead KA, Nuhn L, Sahay G, Cheng H, Jiang S, Ma M, Lytton-Jean A, Vegas A, Fenton P, Levins CG, Love KT, Lee H, Cortez C, Collins SP, Li YF, Jang J, Querbes W, Zurenko C, Novobrantseva T, Langer R, Anderson DG. Combinatorial synthesis of chemically diverse core-shell nanoparticles for intracellular delivery. Proc Natl Acad Sci USA. 2011; 108:12996-13001. [PubMed: 21784981]

113. Davidson BL, McCray PB Jr. Current prospects for RNA interference-based therapies. Nat Rev Genetics. 2011; 12:329-340. [PubMed: 21499294]

114. Hornung V, Bauernfeind F, Halle A, Samstad EO, Kono H, Rock KL, Fitzgerald KA, Latz E. Silica crystals and aluminum salts activate the NALP3 inflammasome through phagosomal destabilization. Nat Immunol. 2008; 9:847-856. [PubMed: 18604214] 


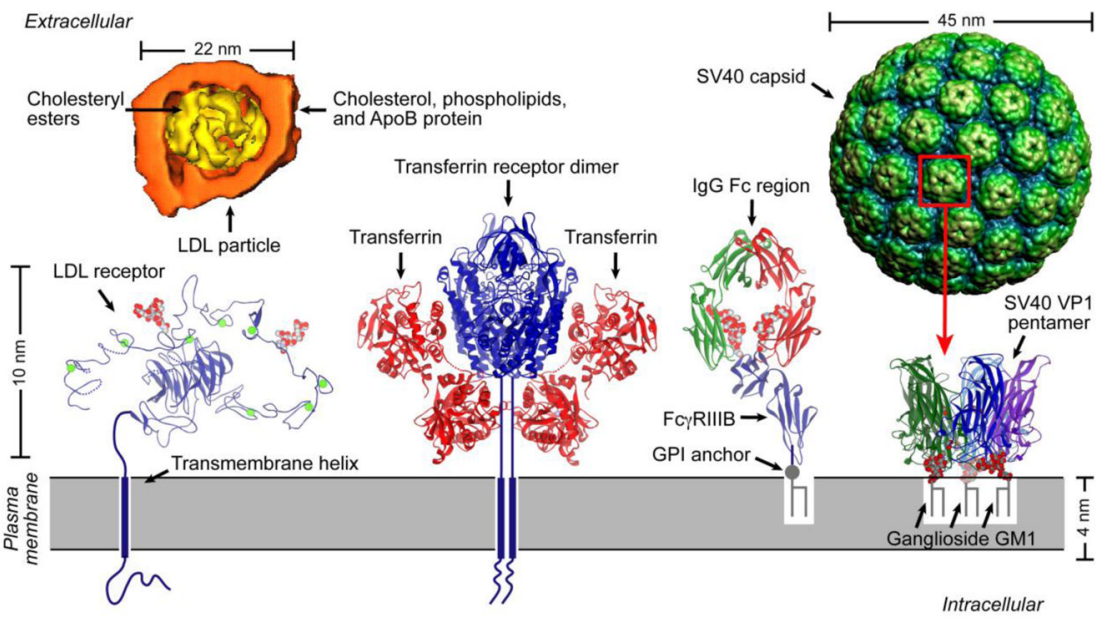

Fig 1.

Natural receptors and ligands involved in receptor-mediated endocytosis. From left to right, $\mathrm{X}$-ray crystal structures of the extracellular domains of the human low-density lipoprotein (LDL) receptor, the human transferrin receptor, and Fc $\gamma$ RIIIB are shown illustrating the nature of association with the plasma membrane. A structure of the ligand LDL determined by electron cryomicroscopy is at the upper left (reduced in scale; image courtesy of Dr. Dr. Wah Chiu, Baylor College of Medicine). Other ligands shown from left to right include receptor-bound transferrin, receptor-bound Fc region of human IgG, the SV40 capsid (reduced in scale; image courtesy of Dr. Ten Feizi, Imperial College, London), and the VP1 pentamer of the SV40 capsid bound to the head group of ganglioside GM1. 


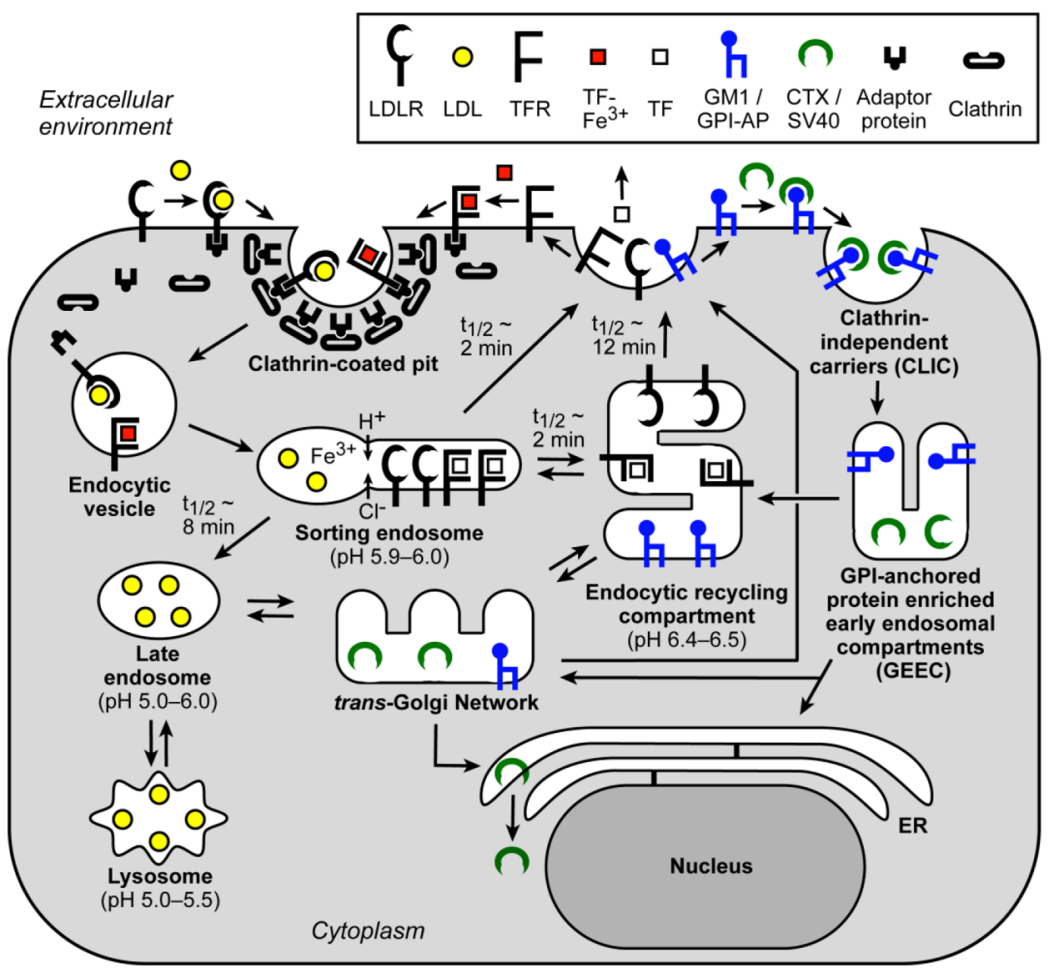

Fig 2.

Endocytic trafficking of receptors and ligands. This model illustrates uptake of low-density lipoprotein (LDL) mediated by the LDL receptor (LDLR), diferric transferrin ( $\mathrm{TF}-\mathrm{Fe}^{3+}$ ) internalized by the transferrin receptor (TFR), entry of cholera toxin (CTX) and simian virus-40 (SV40) after binding to ganglioside GM1, and trafficking of glycosylphosphatidylinositol-anchored proteins (GPI-AP). Ligand-bound LDLR and TFR undergo clathrin-mediated endocytosis, whereas binding of CTX and SV40 to GM1 primarily results in endocytic uptake via clathrin-independent carriers (CLIC) and trafficking through GPI-enriched endocytic compartments (GEEC). The receptors undergo plasma membrane recycling, LDL is degraded in lysosomes, and transferrin remains bound to its receptor, releasing iron in sorting endosomes. CTX and SV40 traffic to the ER and penetrate into the cytosol, resulting in toxicity or infection respectively. The $\mathrm{t}_{1 / 2}$ and $\mathrm{pH}$ values are approximate and cell-type dependent. 


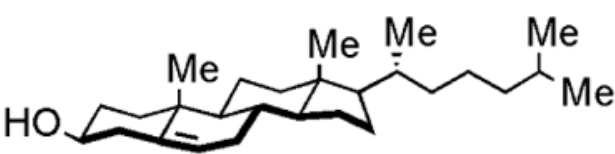

Cholesterol

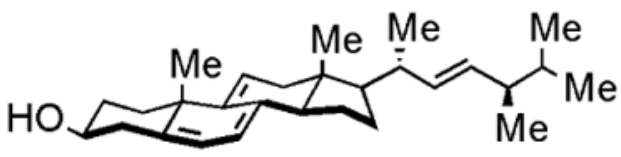

Dehydroergosterol

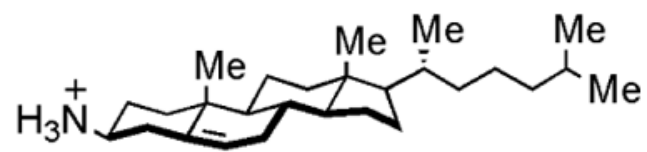

Cholesterylamine<smiles>Cc1cc(C)n(C)c1-c1c(C)cc(C)n1[B-](F)(F)F</smiles>

BODIPY cholesterol

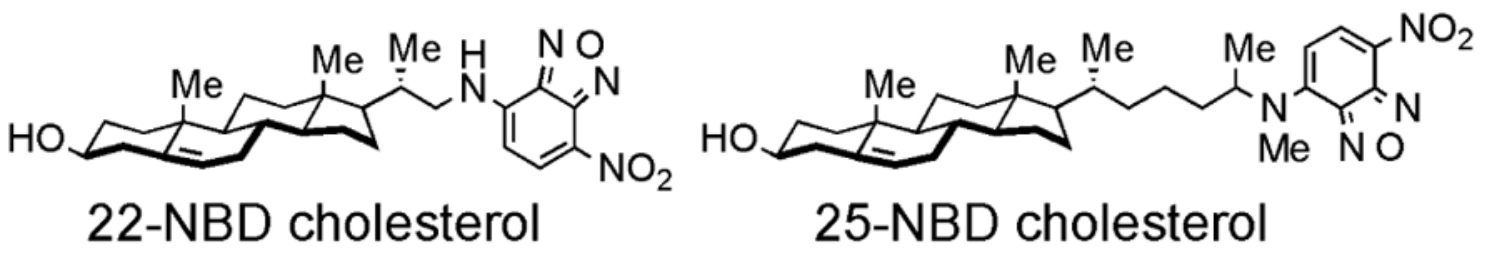

\section{Pennsylvania}



Fig. 3.

Structures of cholesterol, cholesterylamine, and representative fluorescent analogues. 

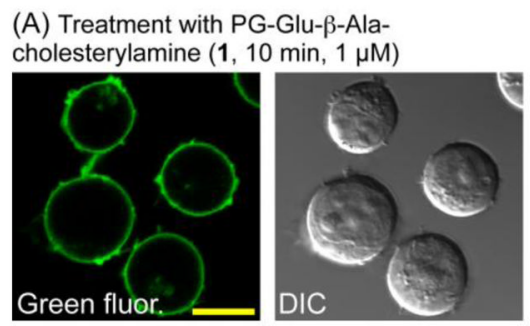

(B) Treatment with PG-Glu- $\beta$-Alacholesterylamine $(\mathbf{1}, 1$ hour, $1 \mu \mathrm{M})$

(C) Treatment with Transferrin-AlexaFluor-488 (5 min, $500 \mathrm{nM}$ ) and Dil-LDL (10 min, $10 \mu \mathrm{g} / \mathrm{mL}$ )



(D) Treatment with PG-Glu- $\beta$-Ala-cholesterylamine $(1,1$ hour, $1 \mu \mathrm{M})$ and Transferrin-AlexaFluor-647 (5 min, $500 \mathrm{nM}$ )

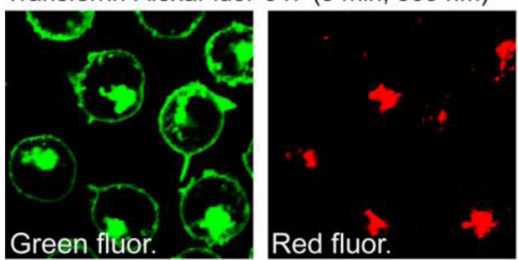

(E) Treatment with 22-NBD cholesterol $(10 \mu \mathrm{M}, 10 \mathrm{~min})$
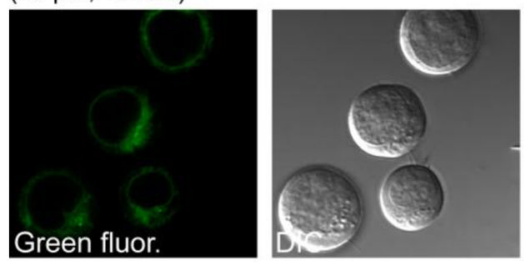
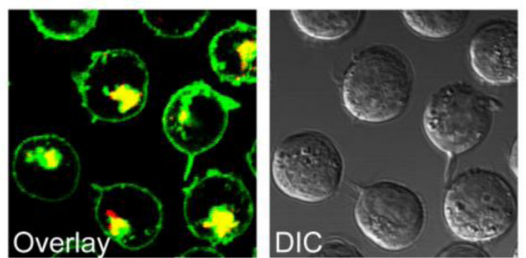

(F) Treatment with 22-NBD cholesterol (10 $\mu \mathrm{M}, 1$ hour)
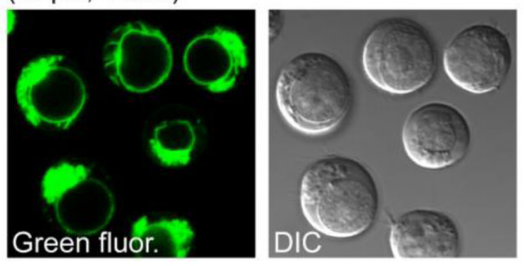

Fig. 4.

Confocal laser scanning and differential interference contrast microscopy of living Jurkat lymphocytes treated with fluorescent probes. These micrographs illustrate the rapid binding of the green fluorescent cholesterol mimic 1 to cellular plasma membranes (panel A) and the accumulation of this compound in early/recycling endosomes (panels B and D). A

comparison of the divergent trafficking of green fluorescent transferrin-AlexaFluor-488 and red fluorescent DiI-LDL is shown in panel C. In panel D, extensive colocalization of green fluorescent 1 with red fluorescent transferrin-AlexaFluor-647 is observed. In contrast, green fluorescent 22-NBD cholesterol does not remain associated with cellular plasma membranes and traffics to the Golgi apparatus and nuclear membrane (panels E-F). The Leica SPE microscope settings in panels $\mathrm{A}, \mathrm{B}, \mathrm{E}$, and $\mathrm{F}$ are identical (high resolution $3 \times$ scans). The images shown in panels $\mathrm{C}$ and $\mathrm{D}$ were acquired as identical rapid single scans for examination of colocalization of the red and green channels. Scale bar: $10 \mu \mathrm{m}$. 


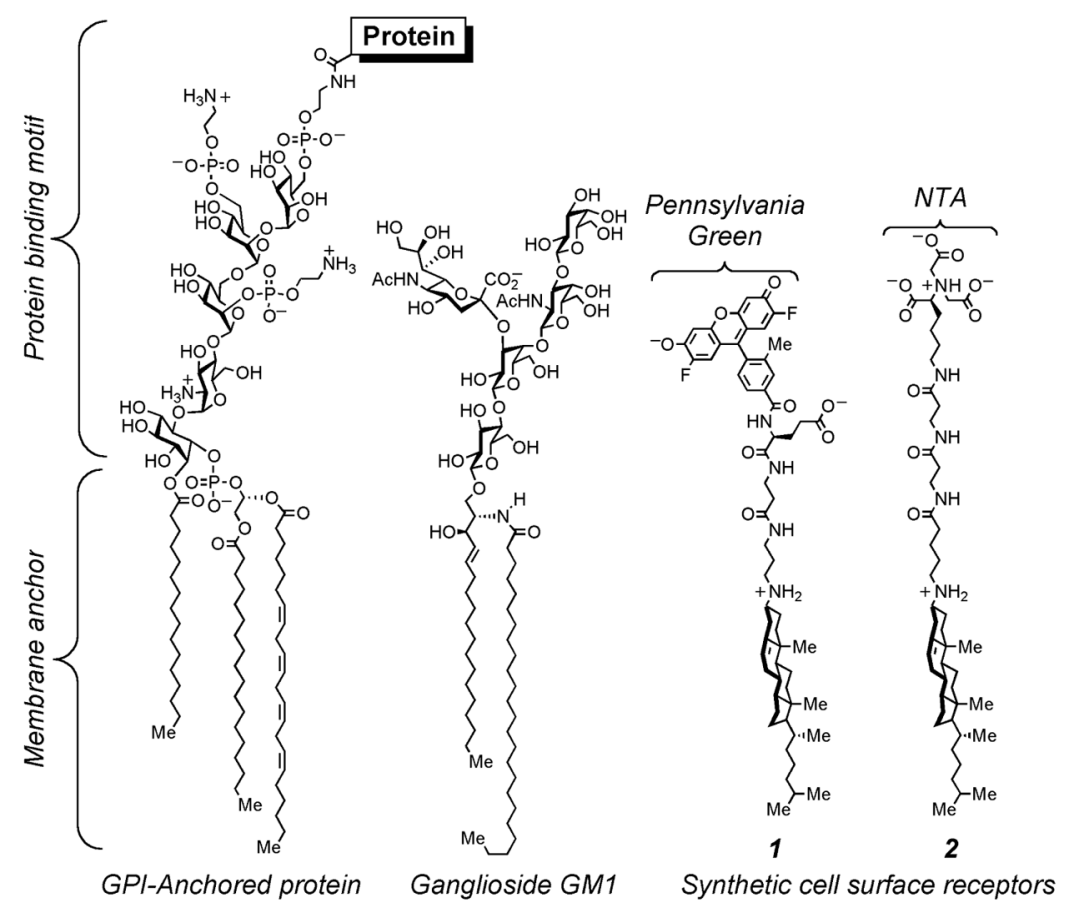

Fig. 5.

Structures of the GPI-anchor of human erythrocyte acetylcholinesterase as a prototypical membrane anchor found in GPI-linked receptors, the small natural receptor ganglioside GM1, and examples of small synthetic cell surface receptors $(\mathbf{1}, \mathbf{2})$. 
(A) Treatment with the synthetic receptor PG-Glu- $\beta$-Ala-cholesterylamine $(1,1$ hour, $1 \mu \mathrm{M})$ followed by antifluorescein IgG-Cy5 (20 min, $0.5 \mu \mathrm{M})$

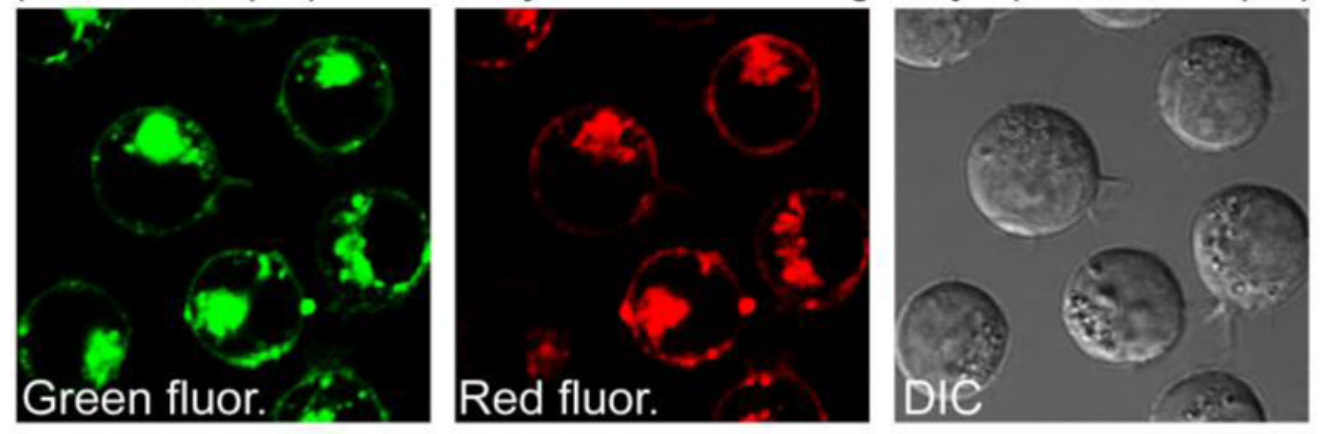

(B) Treatment with the synthetic receptor PG-Glu- $\beta$-Ala-cholesterylamine $(1,1$ hour, $1 \mu \mathrm{M})$ followed by antifluorescein IgG-Cy5 (4 hours, $0.5 \mu \mathrm{M})$

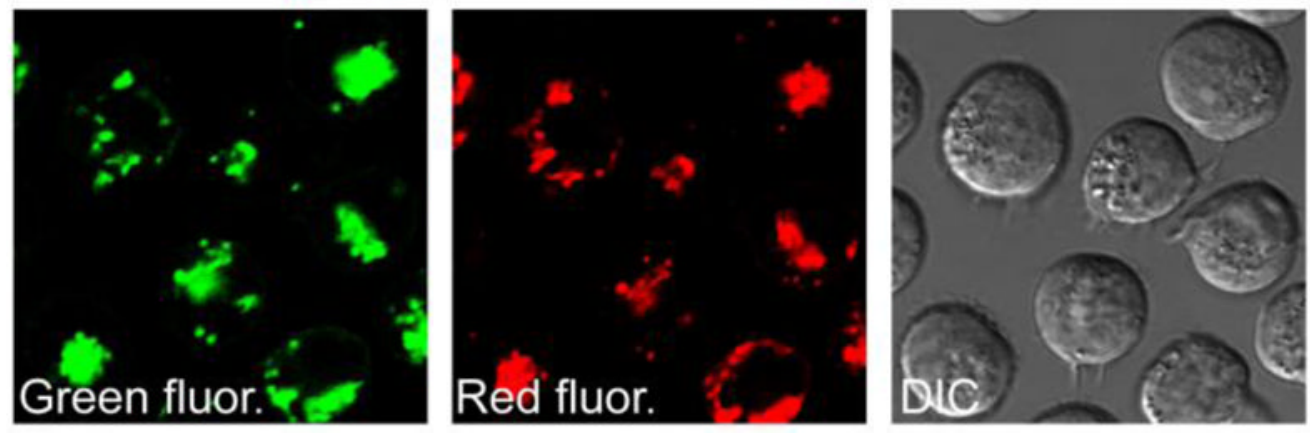

(C) Treatment with antifluorescein IgG-Cy5 alone (4 hours, $0.5 \mu \mathrm{M})$
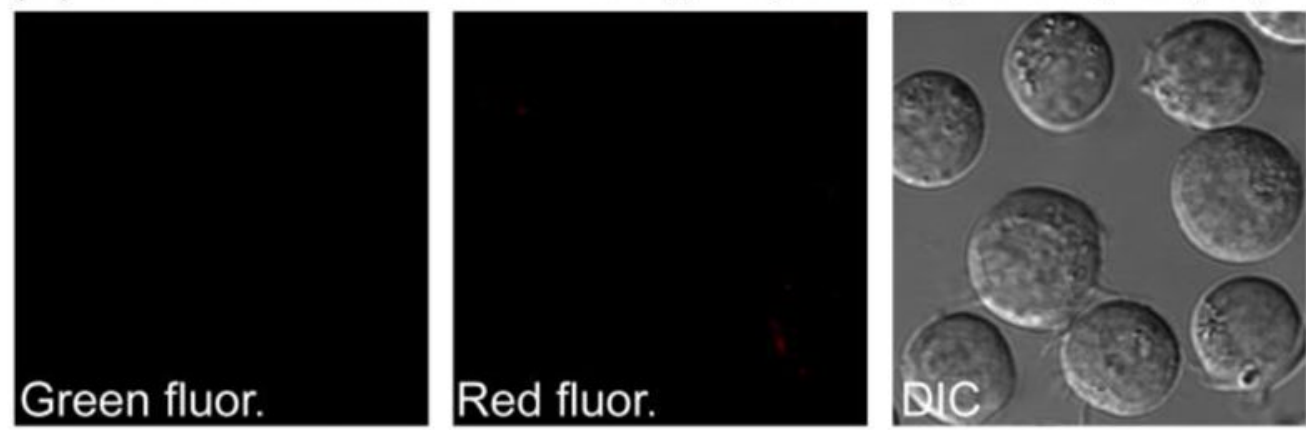

Fig. 6.

Confocal laser scanning and DIC micrographs of Jurkat lymphocytes treated with the green fluorescent synthetic receptor PG-Glu- $\beta$-Ala-cholesterylamine (1) followed by rabbit antifluorescein $\operatorname{IgG}$ conjugated to the red fluorescent $\mathrm{Cy} 5$ fluorophore. 
(A)

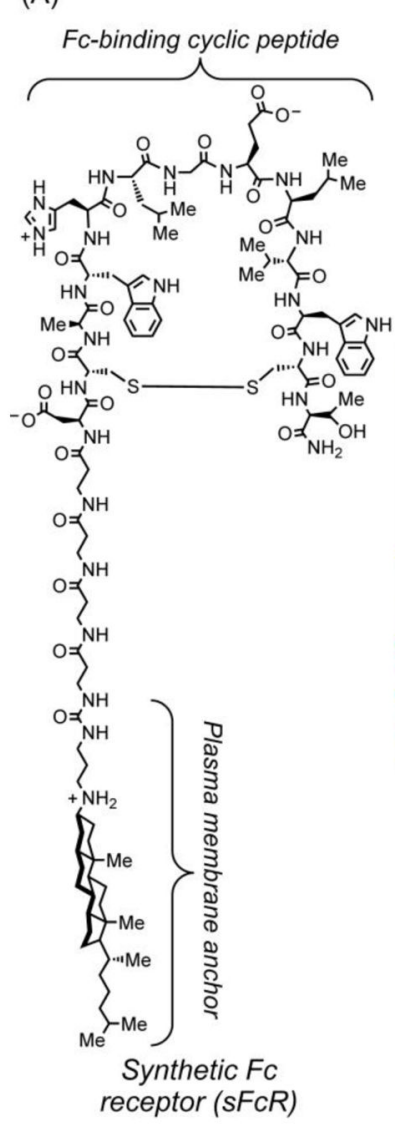

(B)
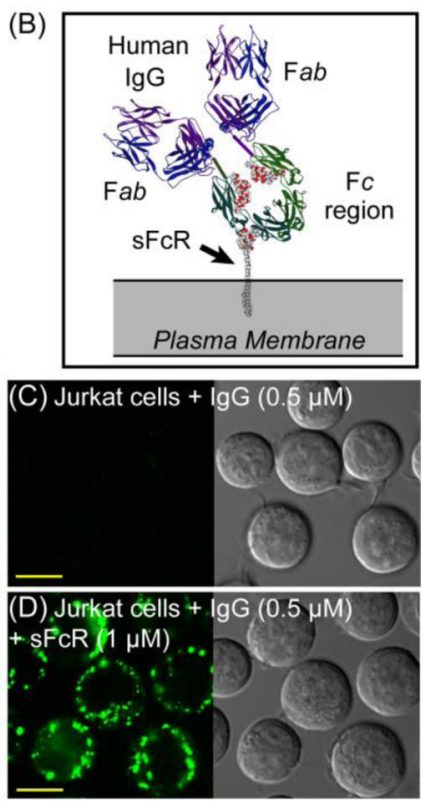

(E)

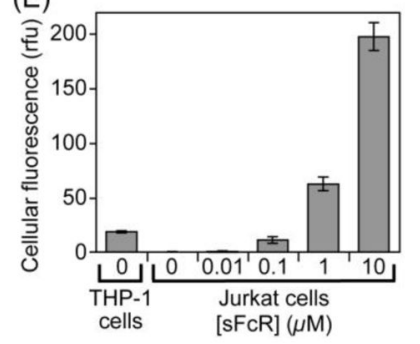

Fig. 7.

Panel A: Structure of a synthetic Fc receptor (sFcR). Panel B: Model of $s F c R$ embedded in the plasma membrane and bound to the Fc region of human IgG. Panels C-D: confocal laser scanning (left) and differential interference contrast (right) micrographs of Jurkat lymphocytes treated for 4 hours as shown. Scale bar: $10 \mu \mathrm{m}$. Panel E: Cellular uptake of fluorescent human $\operatorname{IgG}(0.5 \mu \mathrm{M}, 4$ hours $)$ by THP-1 cells and Jurkat cells treated with sFcR as quantified by flow cytometry. 
(A)

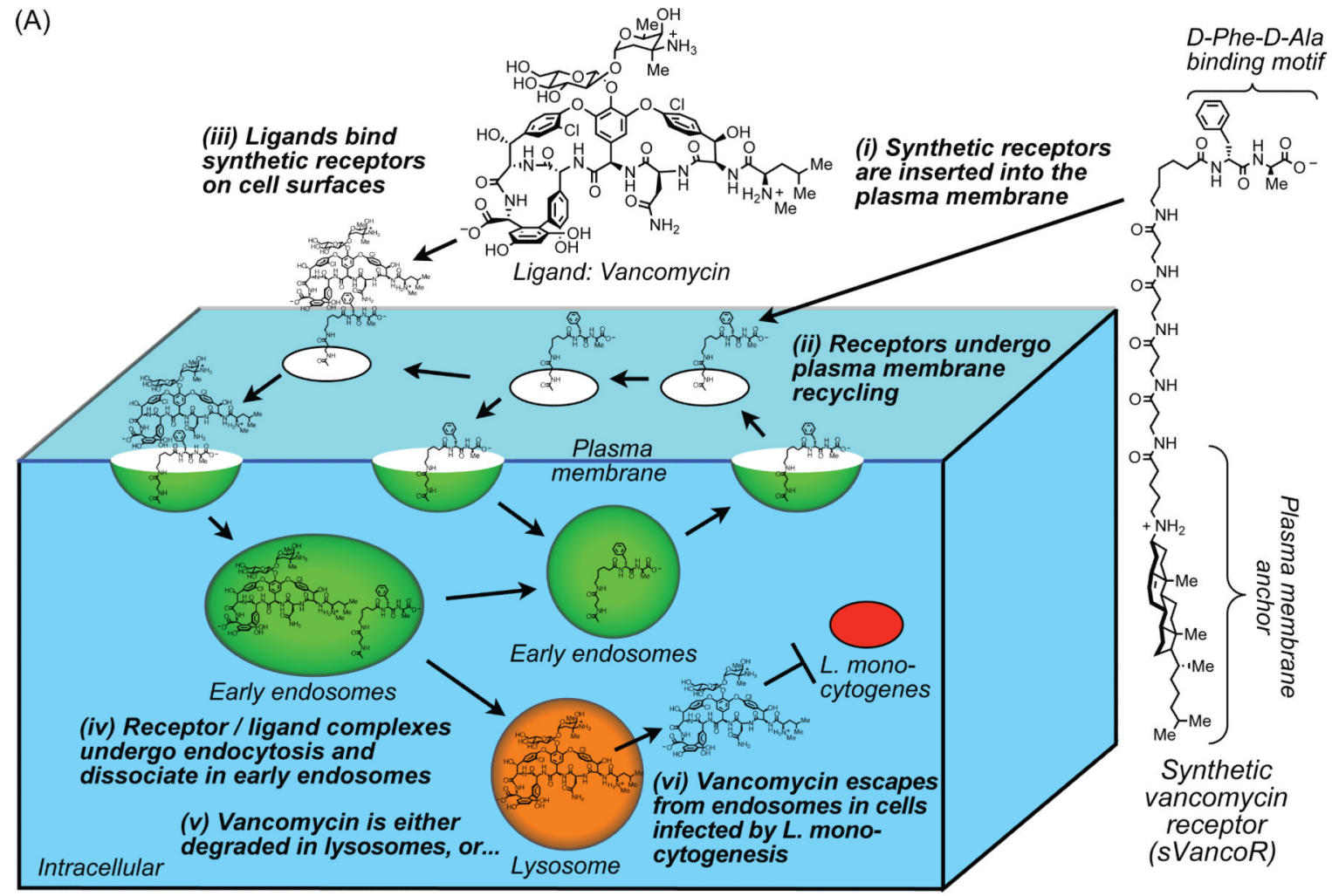

Mammalian cell
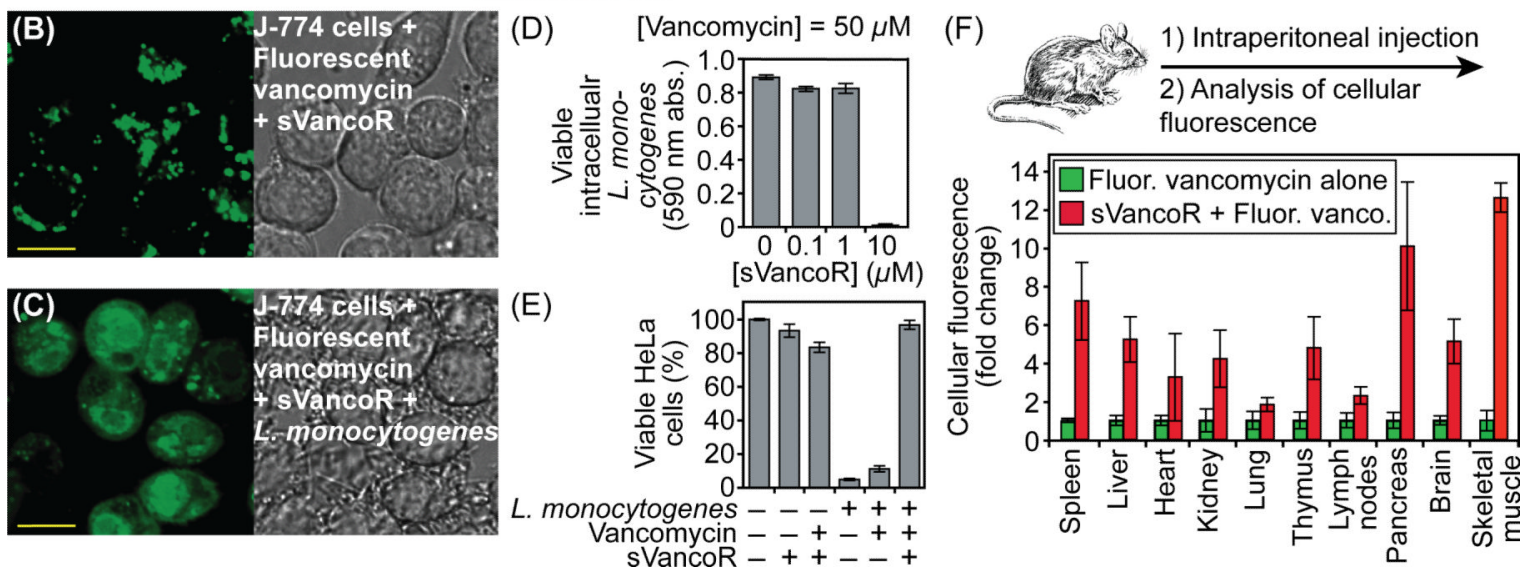

Fig. 8.

Panel A: Structure of the synthetic vancomycin receptor (sVancoR) and a model illustrating synthetic receptor-mediated delivery of the antibiotic vancomycin. Panels B-C: Confocal laser scanning (left) and differential interference contrast (right) microscopy of living J-774 macrophages alone (Panel B) and infected with L. monocytogenes (Panel C). Prior to microscopy, sVancoR $(10 \mu \mathrm{M})$ was added to cells for 1 hour at $37^{\circ} \mathrm{C}$, cells were washed, and fluorescent vancomycin conjugate $(3.6 \mu \mathrm{M})$ was added for 2 hours at $37^{\circ} \mathrm{C}$. Scale bar: $10 \mu \mathrm{m}$. Panel D: Eradication of intracellular L. monocytogenes in HeLa cells dependent on the concentration of sVancoR as determined by subculture of bacteria. Panel E: Treatment with sVancoR enables vancomycin to prevent toxicity of $L$. monocytogenes to HeLa host cells. Panel F: Distribution of fluorescent vancomycin in mice 8 hours after intraperitoneal injection as shown. Fluorescence of cells isolated from tissues was analyzed by flow cytometry. 


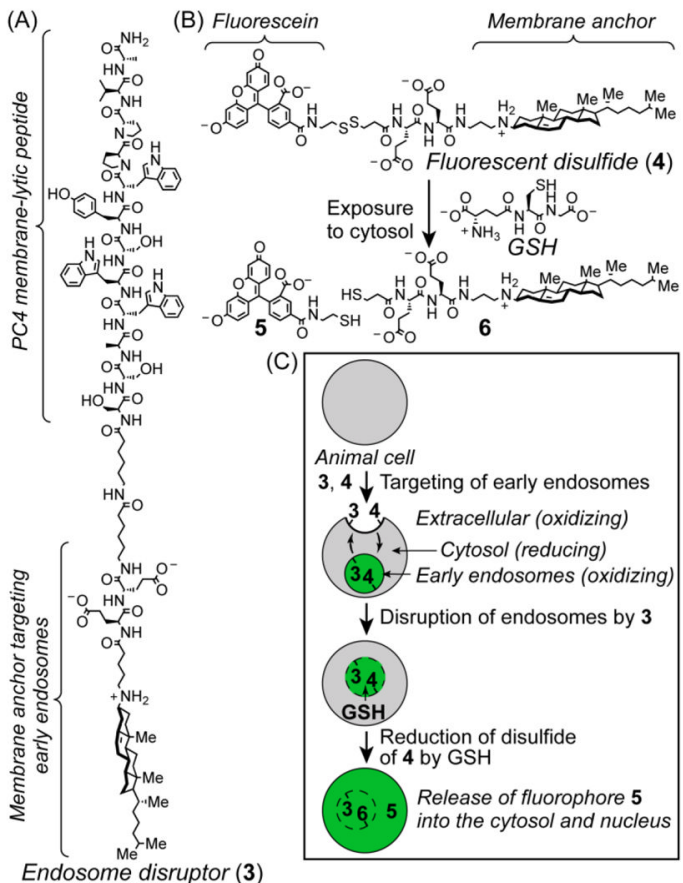

(D) Jurkat cells treated with (D) Jurkat cells treated with
fluorescent disulfide (4) alone

(E) Fluorescent disulfide (4) +

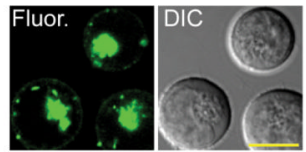

endosome disruptor (3)

(F) Efficacy in Jurkat lymphocytes

after treatment for $14 \mathrm{~h}$

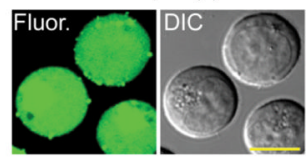

G) Toxicity to Jurkat cells

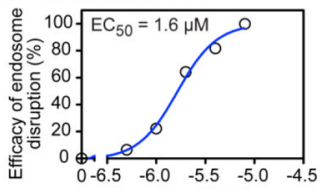

after treatment for $48 \mathrm{~h}$

@ 100 -



$\log [3](\mathrm{M})$

$\log [3](M)$

Fig. 9.

Structures of the cholesterylamine-PC4 endosome disruptor (3, panel A), a fluorescent disulfide-linked cholesterylamine (4, panel B), and products of cleavage of $\mathbf{4}$ by reduced glutathione (GSH, panel B). Panel C: Proposed mechanism of release of fluorescent probe 5 upon disruption of early endosomes. Panels D-E: Confocal fluorescence (left) and DIC (right) micrographs of living Jurkat lymphocytes treated with $4(2.5 \mu \mathrm{M})$ for 12 hours. In Panel E, cells were additionally treated with endosome disruptor $3(2 \mu \mathrm{M})$. Scale bars $=10$ $\mu \mathrm{m}$. Panel F: efficacy of release of fluorescent probe $\mathbf{5}$ as analyzed by flow cytometry. Panel G: Toxicity to Jurkat cells after incubation with $\mathbf{3}$ for 48 hours at $37{ }^{\circ} \mathrm{C}$ as analyzed by flow cytometry. 